\title{
Research Progress of Chitosan-Based Biomimetic Materials
}

\author{
Zhaoyu Zhang, Lingyu Zhang, Chengpeng Li, Xiangyu Xie, Guangfa Li, Zhang Hu * and Sidong Li
}

\author{
Faculty of Chemistry and Environmental Science, Guangdong Ocean University, Zhan Jiang 524088, China; \\ zhangzy227@163.com (Z.Z.); zhangly175@163.com (L.Z.); 1cp0802@126.com (C.L.); \\ xiexiangyu1@stu.gdou.edu.cn (X.X.); lgf0719@163.com (G.L.); sidongligdou@163.com (S.L.) \\ * Correspondence: huzhang@gdou.edu.cn
}

Citation: Zhang, Z.; Zhang, L.; Li, C.; Xie, X.; Li, G.; Hu, Z.; Li, S. Research Progress of Chitosan-Based Biomimetic Materials. Mar. Drugs 2021, 19, 372. https://doi.org/ $10.3390 /$ md19070372

Academic Editor: Hitoshi Sashiwa

Received: 30 May 2021

Accepted: 24 June 2021

Published: 27 June 2021

Publisher's Note: MDPI stays neutral with regard to jurisdictional claims in published maps and institutional affiliations.

Copyright: (c) 2021 by the authors. Licensee MDPI, Basel, Switzerland. This article is an open access article distributed under the terms and conditions of the Creative Commons Attribution (CC BY) license (https:/ / creativecommons.org/licenses/by/ $4.0 /)$.

\begin{abstract}
Chitosan is a linear polysaccharide produced by deacetylation of natural biopolymer chitin. Owing to its good biocompatibility and biodegradability, non-toxicity, and easy processing, it has been widely used in many fields. After billions of years of survival of the fittest, many organisms have already evolved a nearly perfect structure. This paper reviews the research status of biomimetic functional materials that use chitosan as a matrix material to mimic the biological characteristics of bivalves, biological cell matrices, desert beetles, and honeycomb structure of bees. In addition, the application of biomimetic materials in wound healing, hemostasis, drug delivery, and smart materials is briefly overviewed according to their characteristics of adhesion, hemostasis, release, and adsorption. It also discusses prospects for their application and provides a reference for further research and development.
\end{abstract}

Keywords: chitosan; biomimetic materials; mussels; cell matrix

\section{Introduction}

Chitin (CT), the second most abundant natural polysaccharide on earth, after cellulose, is a major structural component in the exoskeletons of a variety of organisms, including protists, diatoms, sponges, arthropods, molluscs, insects, and arachnids, especially seafood, such as shrimp and crab [1-5]. Traditionally, CT was isolated on a large scale from the exoskeletons of fungal organisms and crustaceans. Its extraction includes the chemical method, microbial fermentation, and bioenzymatic hydrolysis [1,6,7]. Chitosan (CS), a deacetylated derivative of chitin, has net cationicity and a variety of functional groups, which can form electrostatic complexes or multilayer structures with other negatively charged substances or natural polymers. In recent years, it has been widely used in many fields, such as tissue engineering, wound healing, drug transportation, adhesives, and adsorption materials, due to its good biocompatibility and biodegradability, safety and non-toxicity, broad-spectrum antibacterial properties, and hemostasis. Additionally, it is easy to process it into gels, membranes, nanofibers, stents, and other forms [8-14].

Bionics is an emerging discipline that studies the structure, function, and optimization of biomaterial systems through the intersection of biology, chemistry, and physics. It uses active substances derived from nature to design various structural and functional materials through the principle of bionics. In recent years, it has become a rapidly developing research field [15-17]. In most cases, bionics does not mean directly copying the structure of biological materials; instead, guiding principles are extracted from biological systems for the artificial synthesis of functional materials with relevant characteristics [18-20]. This review focuses on the imitation of unique structures and functions of some natural organisms, such as bivalves, biological cell substrates, desert beetles, and honeycomb structures of bees, and the preparation of functional materials with related properties and their derivatives, using CS as the matrix material (Figure 1). The applications of biomimetic materials in wound healing, hemostasis, drug delivery, and smart materials were reviewed according to their unique characteristics of adhesion, hemostasis, release, 
and adsorption. Meanwhile, to better understand the role of CS in biomedicine, tissue engineering, adsorption materials, and other fields, the prepared CS-based biomimetic materials were briefly summarized according to their forms, including scaffold, hydrogel, film, and composite material (Table 1).

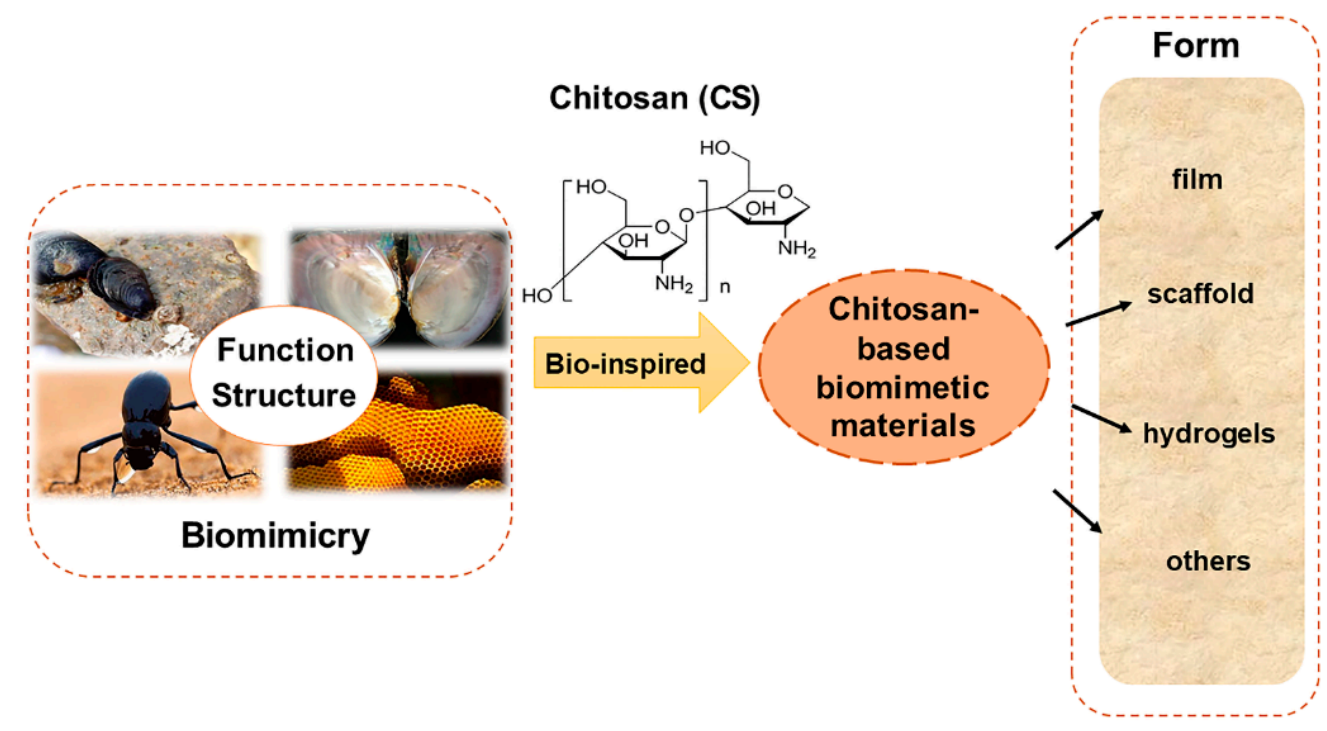

Figure 1. The chitosan-based biomimetic materials and the forms of material prepared.

Table 1. Proposed applications of chitosan-based materials based on forms.

\begin{tabular}{|c|c|c|c|}
\hline Forms & Composites & Applications & Ref. \\
\hline \multirow{5}{*}{ Scaffold } & $\begin{array}{c}\text { CS, porous poly( } \varepsilon \text {-caprolactone) (PCL), bioactive glass }(\mathrm{BG}) \\
\text { polydopamine (PDA) }\end{array}$ & bone tissue engineering & [21] \\
\hline & CS, graphene oxide (GO) & bone tissue engineering & [22] \\
\hline & CS, poly (L-lactic acid) aligned microfibrous bundle & bioengineering & [23] \\
\hline & $\begin{array}{l}\text { CS, poly (methyl methacrylate-co-methacrylic acid) } \\
\text { (P[MMA-co-MAA]), carbodiimide-crosslinker }\end{array}$ & bone tissue engineering & [24] \\
\hline & $\begin{array}{l}\text { CS, honeycomb porous carbon (HPC), nano-sized hydroxyapatite } \\
\text { (nHA), }\end{array}$ & bioengineering & [25] \\
\hline \multirow{11}{*}{ Hydrogel } & CS, catechol & biomedical fields & [26] \\
\hline & $\begin{array}{l}\text { CS, CS-methacrylate (CS-MA), dopamine (DA), N-methylol } \\
\text { acrylamide (NMA) }\end{array}$ & wound healing & [27] \\
\hline & CS, HBC, DOPA & wound dressing & [28] \\
\hline & CS, DA chloride & wound healing & [29] \\
\hline & CS, catechol & biomedical fields & [30] \\
\hline & CS, catechol & biomedical fields & [31] \\
\hline & $\begin{array}{l}\text { tetra-succinimidyl carbonate polyethylene glycol (PEG-4S), } \\
\text { thiol-grafted mussel inspired catechol conjugated chitosan (CSDS) }\end{array}$ & wound healing & [32] \\
\hline & CS, methacrylate modified CS, gelatin & wound healing & {$[33]$} \\
\hline & CS-c, thiolated pluronic F-127 & tissue engineering & [34] \\
\hline & $\begin{array}{l}\text { 3, 4-dihydroxyhydrocinnamic acid glycol chitosan(g-CS), CS catechol } \\
\text { (CS-c) }\end{array}$ & biomedical fields & [35] \\
\hline & CS, catechol, diatom & biomedical fields & [36] \\
\hline
\end{tabular}


Table 1. Cont.

\begin{tabular}{|c|c|c|c|}
\hline Forms & Composites & Applications & Ref. \\
\hline \multirow{9}{*}{ Hydrogel } & $\begin{array}{c}\text { chitosan quaternary ammonium salt (HTCC), oxidized } \\
\text { dextran-dopamine (OD-DA) }\end{array}$ & wound healing & [37] \\
\hline & glycol chitosan (GC), ciprofloxacin (Cip), PDA nanoparticles (NPs) & wound healing & [38] \\
\hline & $\begin{array}{l}\text { hydroxybutyl chitosan (HBC),L-dopamine (L-DOPA), } \varepsilon \text {-poly-L-lysine } \\
\text { (EPL) }\end{array}$ & wound healing & [39] \\
\hline & CS-C, $\beta$ glycerol phosphate $(\beta-G P)$, oyster peptides $(O P)$ & wound dressing & {$[40]$} \\
\hline & hydrocaffeic acid (HCA)-CS, iron oxide $\left(\gamma-\mathrm{Fe}_{2} \mathrm{O}_{3}\right) \mathrm{MNPs}$ & biomedical fields & {$[41]$} \\
\hline & CS, oxidized hyaluronic acid (HAox) catechol terpolymer, Fe & wound dressing & [42] \\
\hline & CS, collagen & biomedical fields & [43] \\
\hline & CS, gelatin, compounded calcium phosphate (CCP) & bone tissue engineering & [44] \\
\hline & $\begin{array}{l}\text { combiningcarboxymethyl chitosan (CMCh), amorphous calcium } \\
\text { phosphate (ACP) }\end{array}$ & bone tissue engineering & {$[45]$} \\
\hline \multirow{15}{*}{ Film } & CS, layered double hydroxides (LDHs), & materials design & {$[46]$} \\
\hline & $\mathrm{CS}, \mathrm{CaCO}_{3}, \mathrm{Al}_{2} \mathrm{O}_{3}$ alumina platelets & hybrid materials & [47] \\
\hline & CS, PDA, silk fibroin nanofibers (SF) & biomedical fields & [48] \\
\hline & CS, delignificated nano-cellulose (DNLC), $\mathrm{MoS}_{2}$ & materials & [49] \\
\hline & CS, HCA, BGNP, catechol & biomedical fields & {$[50]$} \\
\hline & CS, alumina sheets & bionanocomposite & [51] \\
\hline & CS, montmorillonite (MTM) & bionanocomposite & [52] \\
\hline & O-carboxymethyl CS (CCS), MMT & fireproof materials & [53] \\
\hline & CS, MMT & fireproof materials & [54] \\
\hline & CS, poly (vinyl acetate) (PVAc), tetracycline (TC) & biomedical fields & [55] \\
\hline & $\begin{array}{l}\text { CCS, 2-methylacrylloxyethyl phosphorycholine (MPC), PDA, } \\
\text { GRGDY peptide }\end{array}$ & biomedical fields & [56] \\
\hline & CS, MTM, metal ions & bionanocomposite & [57] \\
\hline & CS-gelatin (C:G), anodic alumina molds (AAM) & bone tissue engineering & [58] \\
\hline & CS, poly (vinylidene fluoride) (PVDF) & wastewater treatment & [59] \\
\hline & CS, poly (ethylene glycol) diglycidyl ether (PEGDGE, Mn = 500) & glycoproteomics & [60] \\
\hline \multirow{12}{*}{ Others } & CS-c, iron oxide nanoparticles (IONPs) & biomedical fields & [61] \\
\hline & carbon nanotubes (CNT), carboxymethyl CS, PDA & efficient adsorbents & [62] \\
\hline & $\mathrm{CS}, \mathrm{Fe}_{3} \mathrm{O}_{4}, \mathrm{PDA}$ & efficient adsorbents & {$[63]$} \\
\hline & $\mathrm{CMC}, \mathrm{Fe}_{3} \mathrm{O}_{4}, \mathrm{PDA}$ & efficient adsorbents & {$[64]$} \\
\hline & $\mathrm{CS}, \mathrm{CaCl}_{2}, \mathrm{Na}_{2} \mathrm{HPO}_{4}$ & bone tissue engineering & [65] \\
\hline & CS, hydroxyapatite (HA), & heavy metal removal & [66] \\
\hline & CS, cis-butenediolic acid (maleic acid, MAc) & biomedical applications & [67] \\
\hline & CS, fragments of human collagen I & biomedical fields & [68] \\
\hline & $\mathrm{CS}$, iron chloride hexahydrate $\left(\mathrm{FeCl}_{3} \cdot 6 \mathrm{H}_{2} \mathrm{O}\right)$ & microwave absorbing & [69] \\
\hline & $\mathrm{CS}, \mathrm{HCL}, \mathrm{KOH}$ & absorbing materials & [70] \\
\hline & CS, aminomethyl phosphate, $\mathrm{Ti}^{4+}$ & absorbing materials & [71] \\
\hline & $\mathrm{CS}$, hydroxyl-functionalized hexagonal boron nitide (OH-BN) & $\begin{array}{l}\text { environment-friendly } \\
\text { materials }\end{array}$ & [72] \\
\hline
\end{tabular}




\section{Biomaterials Imitating Bivalves}

\subsection{Imitation Mussel Adhesive Material}

Marine mussel organisms possess a solid structure to enable strong, persistent adhesions to various materials in humid environments. It is mediated by a mussel-foot-protein (MFPS) sequence structure containing a large amount of 3,4-dihydroxy phenyl-L-alanine (DOPA) [73-75]. The catechol group is critical to its adhesion mechanism and is considered an ideal candidate for constructing solid matrix adhesion materials [46]. The corresponding CS-catechol conjugate (CS-C) has antifluid adhesion properties and hemostatic ability [76,77]. It can be used as bio-printing materials [78], drug delivery libraries [79], and for nanoparticle surface functionalization [80].

\subsubsection{Hemostatic and Tissue Adhesive Material}

CS-C, inspired by the mussel-adhesive protein, is the closest mimic of mussel adhesion proteins. It was obtained by grafting catechol derivatives to the amino groups of the CS backbone. In addition, CS-C has been widely exploited as general hemostatic materials, adhesives, and nano-particle composites due to its inherent property of immediate complexation with serum proteins. Shin et al. developed self-sealing hemostatic needles and adhesive coatings. The surface of the needle was coated with partially crosslinked catechol-functionalized CS, which could immediately prevent partial bleeding of the injection and may therefore help to prevent complications associated with bleeding in more clinical settings [26]. Combined with the characteristics of biofilms, Han et al. developed a novel dual bionic adhesive hydrogel (DBAH) by free radical polymerization. Specifically, methacrylate (CS-MA), dopamine (DA), and N-methylol acrylamide (NMA) were grafted on CS molecules (Figure 2). Compared with the conventional commercial medical adjuvants, these hydrogels presented excellent hemostatic capability under wet and dynamic motion in vivo [27]. Zhang et al. [28] prepared a hydroxybutyl chitosan-CS-dopamine composite hydrogel with the dopamine self-polymerization method, which was used to dress in vitro hemostatic wounds. The results showed that the composite hydrogel had temperature sensitivity, low hemolysis rate, and a short blood clotting time. Also inspired by MFPS, Han et al. synthesized a series of CS-grafted polypeptide copolymers that showed good biodegradability, low cytotoxicity, and good hemostatic properties, which could also promote the healing of skin wounds and fractures [29]. Kim et al. [30] investigated the enhancement of mucoadhesion properties of CS by catechol coupling. The retention ability of CS-C in the gastrointestinal tract was improved by the formation of irreversible catecholmediated crosslinking with mucin. Inspired by the current obstacles in oral cavity drug delivery, Ryu et al. developed porous spongy-like adhesive materials, a freeze-dried form from the CS-C solution called "Chitoral". Chitoral instantly dissolved upon contacting with saliva in the oral cavity and then formed intermolecular complexes with oral mucins, which were rapidly transformed into an adhesive hydrogel-like material through the synergistic action of covalent cross-linking and physical entanglement [31]. Based on the previous research [81,82], Zeng et al. [32] integrated various functions of other materials to design an injectable double cross-linked hydrogel adhesive, based on tetra-succinimidyl carbonate polyethylene glycol (PEG-4S), and thiol-grafted mussel inspired catechol conjugated CS (CSDS). Related performance evaluation results showed that the mechanical and adhesion properties of double-crosslinked hydrogel have been significantly improved. He et al. fabricated an injectable two-component hydrogel prepared from catechol and methacrylate modified CS/gelatin to solve the current challenges faced by medical adhesives [33]. Instantaneous gelation is required for the practical applications of CS-C as tissue adhesives. Ryu et al. [34] prepared a temperature-sensitive injectable hydrogel with high adhesion by mixing CS-C with thiolated Pluronic F-127. The addition of Pluronic F-127 effectively shortened the gelation time and improved the adhesion property of CS-based hydrogel, which was expected to be used in tissue engineering adhesives and antibleeding materials. 
(a)

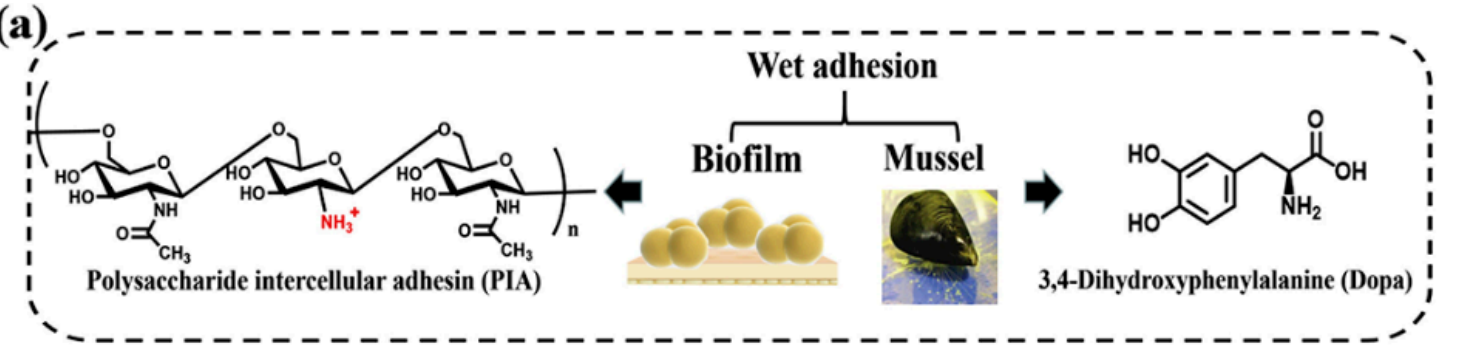

(b)
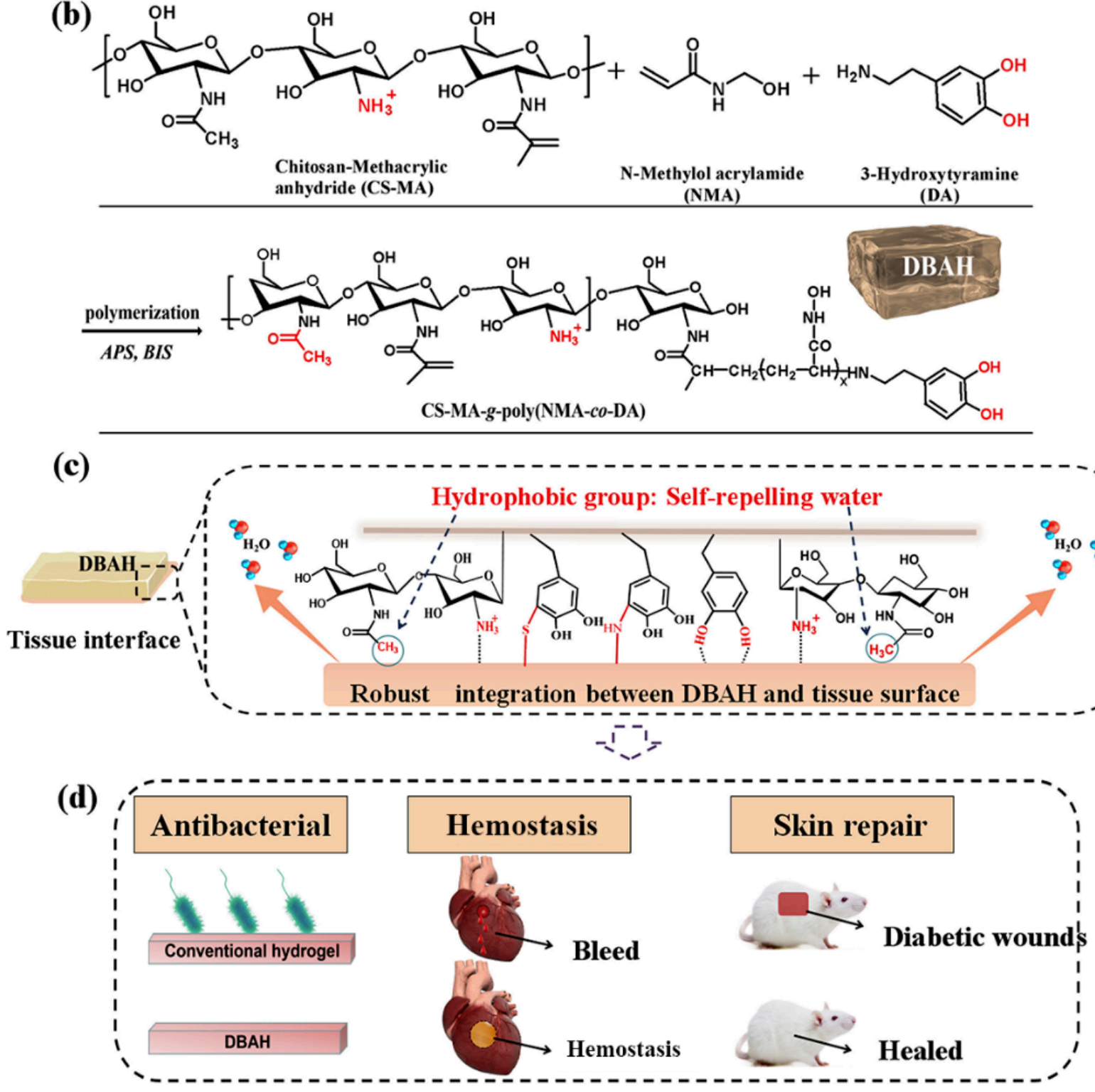

Figure 2. Schematic illustration of design strategy of an engineered biofilm and mussel-inspired dual-bionic adhesive hydrogels (DBAH) and its application for sealing hemostasis and wound healing. (a) The structure of polysaccharide intercellular adhesin (PIA), derived from biofilm, and DOPA, derived from mussel protein, which play a key role in wet adhesion; (b) A biometic biopolymer chitosan, grafted with methacrylate (CS-MA) from PIA; and dopamine, a catecholamine containing a catechol group of DOPA, was conjugated with NMA for hydrogel formation; (c) Schematic illustration of strong underwater bioinspired adhesion base on the self-repelling water function of CS-MA. (d) The multifunctional properties and potential application in in vivo hemorrhage and diabetic wound healing with antibacterial performance. Reproduced with permission from [27], Copyrighter Elsevier 2020. 
Despite its versatility, the practical application of CS-C in clinical practice is limited because it is a highly positively charged polymer that can cause increased severe protein adsorption and trigger an immune response in the body [26,83]. To ameliorate the adverse immune response between polymer materials and proteins, Park et al. proposed a catechol-conjugated glycol CS hemostatic hydrogel inspired from mussel adhesive proteins and compared them with non-glycol CS-C hydrogels to evaluate their immune response, cytotoxicity, adhesion properties, and hemostatic ability. The results showed that glycol CS-C significantly attenuated the immune response. However, the tissue adhesion and hemostatic ability of glycol CS-C were not dramatically improved, and it was speculated that the finding was likely due to the antibiofouling effect of the ethylene glycol group and the reduction of immune cell adhesion [35]. Although significant progress has been made in bioelectronics research in recent years, it is still challenging for self-adhesive bioelectronics to adhere to human tissues and achieve signal detection without external aids. So far, there are only a few reports on self-adhesive bioelectronics, and they are primarily limited to collecting signals on the skin. Applications such as tactile sensors and implanted neural interface electrodes have not been reported. Introducing self-adhesion into currently available bioelectronic materials remains difficult due to the complex application environment and strict requirements, including biocompatibility, biological stability, and wet adhesion ability in the body fluid environment. Xie et al. [84] proposed an approach to regulate the dynamic equilibrium mechanism of phenolquinone redox based on a mussel-like strategy and developed a series of new biomedical hydrogels endowed with bioelectronic self-adhesion and other functional properties, such as super mechanical, self-repair, transparency, antibacterial, high-temperature resistance, frost resistance, and underwater adhesion (Figure 3). Kim et al. [36] provided a new strategy to design marine biomaterial hydrogels synthesized from catechol, CS, and diatom. It was highly stretchable and self-healing and can be utilized for various applications, including stretchable power sources, wearable electronics, and health monitoring systems with artificial intelligence.
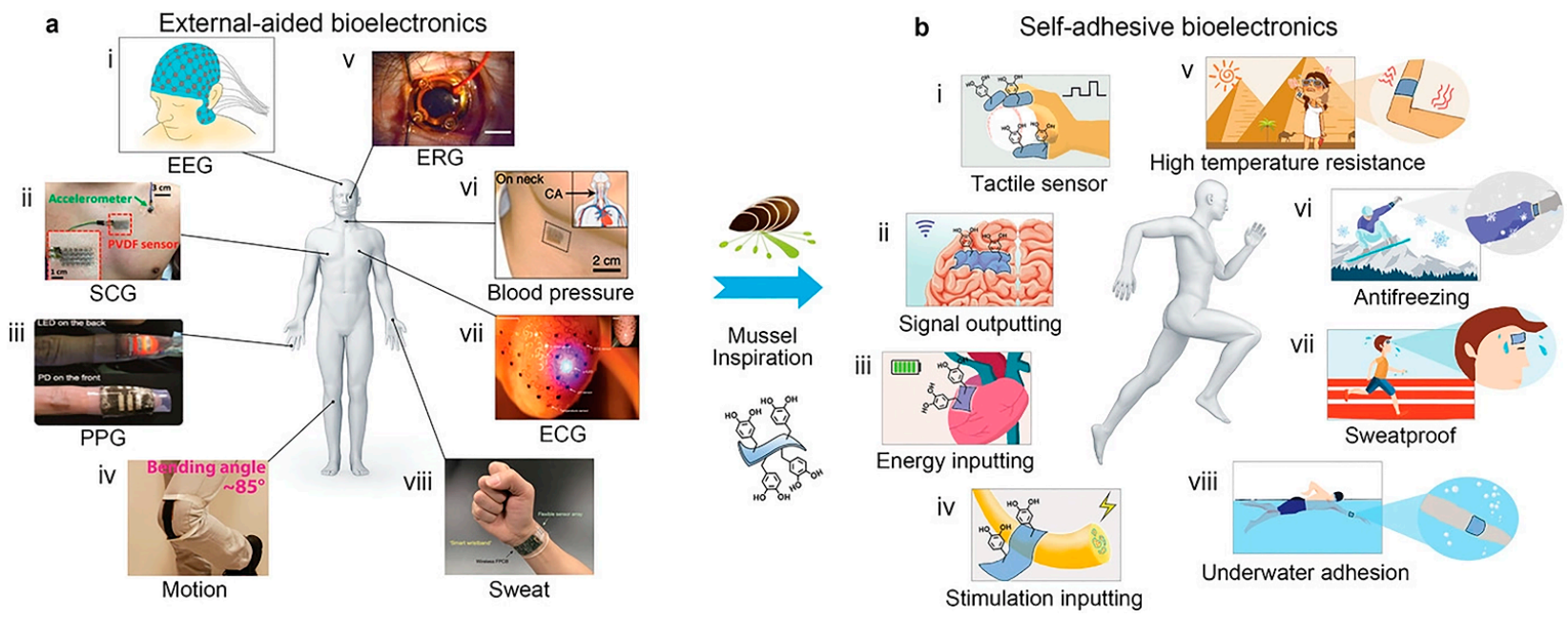

Figure 3. The mussel-like strategy provides novel approaches for wearable/implantable bioelectronics to shift from external auxiliary fixation to convenient and reliable self-adhesion. Reproduced with permission from [84], Copyrighter Wiley 2017.

\subsubsection{Drug Delivery and Active Compound Release Material}

The application of hydrogels in clinical wound treatment-related fields has been reported frequently, but the exploration of intelligent hydrogels that can respond quickly and accurately to complex and multiple stimuli is still a promising strategy. Hu et al. [37] reported a novel design strategy for a double-crosslinked smart hydrogel for local release treatment of bacteria-infected diabetic wounds. First of all, they completed the first crosslinking to prepare hydrogel by a Schiff base reaction between the amino groups $\left(-\mathrm{NH}_{2}\right)$ in the CS quaternary ammonium salt (HTCC) and the aldehyde groups $(-\mathrm{CHO})$ in the oxi- 
dized dextran-dopamine (OD-DA). The second step of cross-linking was completed by the formation mechanism of catechol-catechol adducts in hydrogels [85]. Finally, based on their design strategy, they used a simple hybrid approach to impart antimicrobial and angiogenic efficacy to the hydrogels by loading AgNPs with the antiangiogenic drug deferriamine (DFO). To combat bacterial infections and achieve safe and controllable wound healing, Gao et al. mixed glycol CS (GC) with polydopamine (PDA) nanoparticles (NPs) loaded with ciprofloxacin (Cip) to produce a PDANP-Cip/GC injectable hydrogel. Under nearinfrared light irradiation, this gel cooperated with Gel-Cip to accelerate Cip release and activated photothermal PDA NPs to achieve an efficient sterilization effect and promoted wound healing. Experimental analysis has confirmed its biological safety in vivo [38]. In view of the shortcomings of previously prepared thermosensitive hydroxybutyl CS (HBC) hydrogel carrying antibiotics and growth factors, Tian et al. [39] introducedL-DOPA to improve the adhesion and mechanical properties of HBC on wet tissue surfaces. Additionally, $\varepsilon$-Poly-L-lysine (EPL), an antimicrobial peptide, was introduced to improve its antimicrobial ability in a neutral environment and reduce the potential harm caused by the introduction of antibiotics. By taking advantage of EPL, (L-DOPA)-(EPL)-HBC hydrogels (eLHBC) displayed highly efficient antimicrobial activity against Escherichia coli and Staphylococcus aureus. The bone marrow mesenchymal stem cells (BMSCs) encapsulated into eLHBC could secrete growth factors and promote the migration of fibroblasts. The potential biomaterials of BMSC $\subset$ eLHBC could promote wound healing and skin tissue regeneration (Figure 4). Zhang et al. [40] prepared a CS-based thermo-sensitive hydrogel loading oyster peptide (CS-C/OP/ $\beta$-GP) with a porous three-dimensional network and rapid hemostasis effect by combining catechol-functionalized CS and oyster peptide (OP). The safety evaluation confirmed that the CS-C/OP/ $\beta$-GP hydrogel was non-cytotoxic to L929 fibroblasts. In vitro experiments showed that CS-C/OP/ $\beta$-GP hydrogel could absorb a large amount of water from plasma to concentrate the blood due to its porous structure, polycationic characteristics, and good water absorption capacity, thereby achieving rapid hemostasis. It is speculated that CS-C/OP/ $\beta$-GP hydrogel had good application prospects in the field of medical hemostasis.

\subsubsection{Functional Composite Material}

The properties of mussels and CS molecules can be exploited to obtain composite materials with tunable properties. To explore the potential of catechol-functionalized CS, Ghadban et al. [41] used metal-catechol coordination to design $\mathrm{pH}$-sensitive and magneticresponsive hydrogels and then incorporated iron oxide $\left(\gamma-\mathrm{Fe}_{2} \mathrm{O}_{3}\right) \mathrm{MNPs}$ into the formulation to expand its functions. This strategy made the gel magnetically responsive, increased the mechanical response, and enabled the control of drug release kinetics. Ni et al. prepared a new type of catechol-CS (CCS)-iron oxide NP (IONP) composite material that had a firm surface affinity and significantly improved immobilization under optimal conditions. The loading capacity and remaining activity of the enzyme provided an improved platform for bio-macromolecule immobilization [61]. Zeng et al. [62] combined mussel excitation chemistry and the Michael addition reaction to modify the surface of carboxymethyl CS on multiwalled carbon nanotubes (CNTs) to produce CNT-PDA-CS. Dopamine (DPA) contains a large number of active groups, such as catechol, amino, and (im)amino groups. Under mild alkaline conditions, polydopamine films can be formed on various inorganic and organic materials through spontaneous oxidation polymerization [86,87]. Mussel-inspired polydopamine (PDA)-related materials have attracted interest in the making of multifunctional materials. Wang et al. [63] fabricated a novel magnetic hybrid nano-biosorbent ( $\left.\mathrm{Fe}_{3} \mathrm{O}_{4} @ P D A @ C S\right)$ via Schiff base reaction, which had a strong adsorption capacity and efficient removal of dyes and metals. Lei et al. [64] prepared $\mathrm{Fe}_{3} \mathrm{O}_{4} @ P D A / C M C$ aerogel by the Schiff base reaction between PDA and CMC using a simple method of introducing the polydopamine $\mathrm{Fe}_{3} \mathrm{O}_{4} \mathrm{NPS}$ surface using a mussel-inspired chemistry coating strategy. The experimental results showed that $\mathrm{Fe}_{3} \mathrm{O}_{4} @ \mathrm{PDA} / \mathrm{CMC}$ aerogel adsorbent had excellent magnetic properties and high adsorption capacity (Figure 5). Therefore, it was a high efficiency, 
economical price, and environmental protection material expected to remove dyes from an aqueous solution. Hydroxyapatite (HAP, $\left.\mathrm{Ca}_{10}\left(\mathrm{PO}_{4}\right)_{6}(\mathrm{OH})_{2}\right)$ has been successfully used in many biomedical fields due to its unique biological activity. The bioactive properties of HAP and the enhancement of the mechanical strength of CS provide a new approach for the treatment of damaged hard tissue. Szatkowski et al. [65] selected calcium chloride $\left(\mathrm{CaCl}_{2}\right)$ and disodium hydrogen phosphate $\left(\mathrm{Na}_{2} \mathrm{HPO}_{4}\right)$, which are rarely described as precursors of mineral phases in CS composites in literature, as sources of calcium and phosphorus, or CS as the organic phase to prepare HAP/CS composites. By comparing the HAP/CS (mineral and organic) biomaterials prepared in different proportions, they found that the HAP/CS ratio of $85 / 15$ had the best morphological characteristics (high specific surface area and porosity). In addition, energy dispersive spectrometer (EDS) analysis showed that the precipitated HAP had a calcium/phosphorus ratio similar to that of natural minerals, which confirmed the feasibility of its synthesis process. Li et al. [21] proposed a feasible and effective covalent method for immobilization of CS onto the surface of porous poly( $\varepsilon$-caprolactone) (PCL)/bioactive glass (BG) composite scaffolds using a mussel-inspired PDA coating. The experimental results showed that the scaffolds had obvious advantages compared with the simple physical adsorption CS scaffold, with excellent potential in orthopedic repair.

A

B

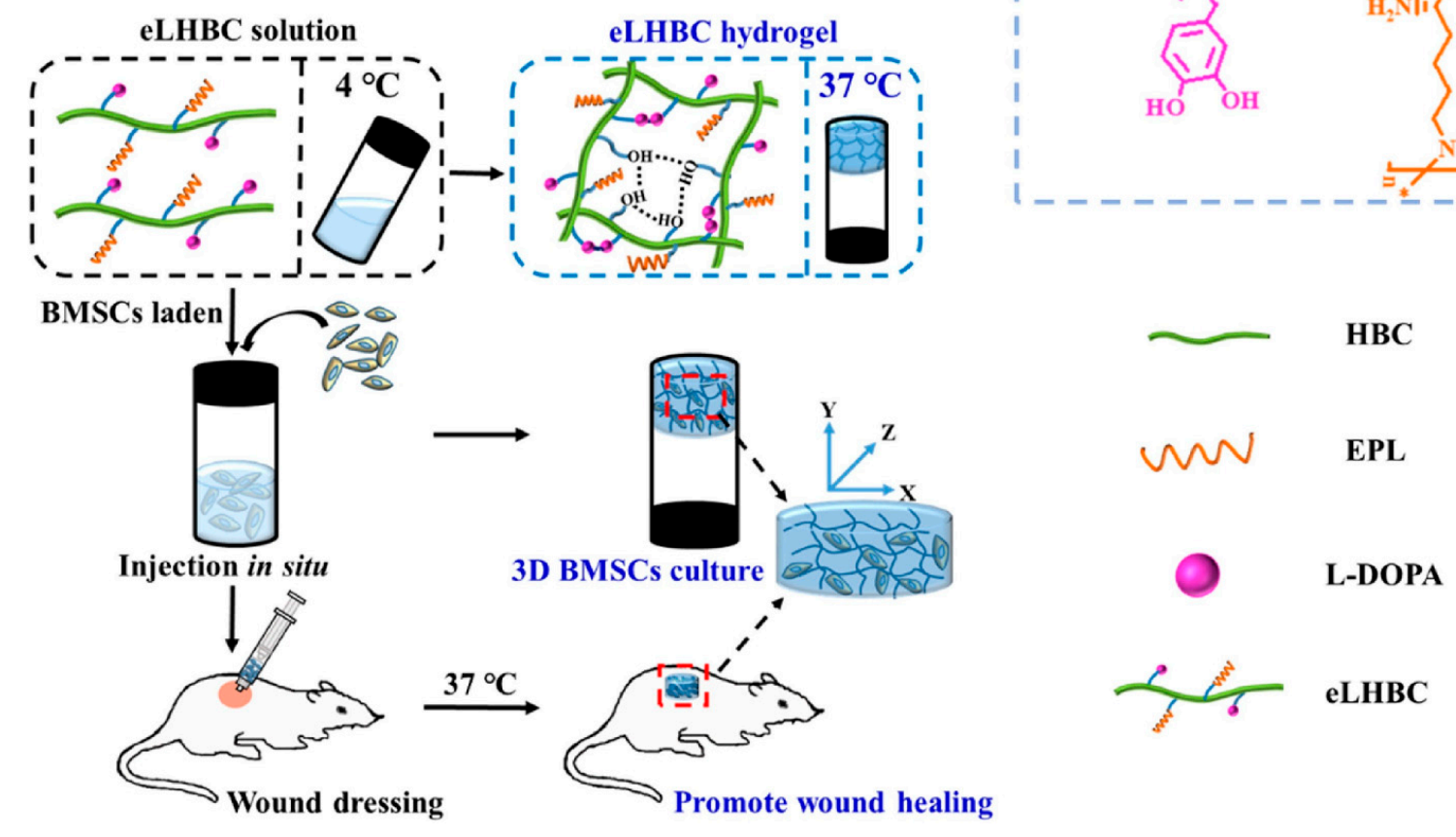

Figure 4. (A) Synthesis scheme of eLHBC conjugate via the binding of carboxyl groups ofL-DOPA and EPL to the $\mathrm{NH}_{2}$ groups of HBC. (B) The formation of eLHBC at $37^{\circ} \mathrm{C}$. BMSCs encapsulated into eLHBC solution at $4{ }^{\circ} \mathrm{C}$ and eLHBC as $3 \mathrm{D}$ BMSCs culture matrix at $37^{\circ} \mathrm{C}$ (BMSCs $\subset$ eLHBC). The BMSCs $\subset$ eLHBC injected with a syringe on the dorsal wound site of rats and used as wound dressing. Reproduced with permission from [39], Copyrighter Elsevier 2021. 


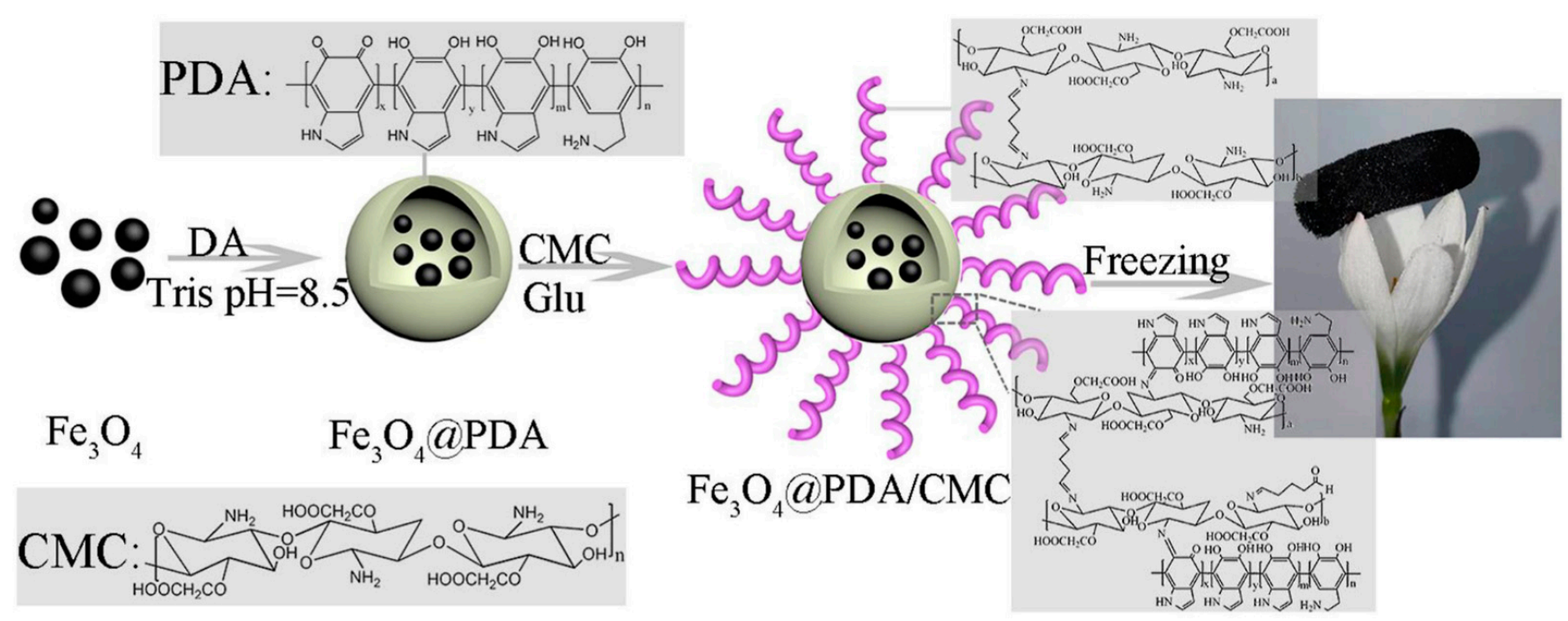

Figure 5. Schematic illustration of the preparation of $\mathrm{Fe}_{3} \mathrm{O}_{4} @ \mathrm{PDA} / \mathrm{CMC}$ aerogel (polydopamine (PDA), dopamine (DA), Tris (hydroxymethyl)aminomethane (Tris), Carboxymethyl chitosan(CMC), and Glutaraldehyde (Glu)). Reproduced with permission from [64], Copyrighter Elsevier 2021.

\subsection{Imitation Pearl Layer Structure Material}

Biomineralization refers to a biological process that forms highly ordered biological materials, such as shells, pearls, enamel, or bones, through the interaction of specific surface binding at the organic-inorganic interface. Because of their specific combination, biominerals have a hierarchical layered structure, as well as mechanical and physical properties, which are more suitable for diversified functional purposes. Nacre is a type of mineralized tissue deposited by many mollusk species (Bivalves and cephalopods) to build the inner layers of their shells. Mature nacre consists of thin layers $(\sim 30 \mathrm{~nm})$ of matrix and thicker layers $(\sim 500 \mathrm{~nm})$ of the calcium carbonate mineral aragonite (lamellae). The matrix layer accounts for about $5 \%$, and calcium carbonate accounts for about $95 \%$. Although proteins account for a small part of the content of biominerals, they directly participate in controlling the growth of biological crystals, thereby enhancing the mechanical properties of biominerals [47,88-92]. In recent years, researchers have used a variety of innovative techniques to simulate the nacreous layer microstructure and produce materials with good mechanical properties.

\subsubsection{Composite Film Material}

Through the bottom-up continuous deposition of organic and inorganic layers under ambient environmental conditions, Bonderer et al. [93] obtained layered hybrid films combining high tensile strength and ductile behavior. Ma et al. successfully deposited CS and PDA on silk fibroin nanofibers through layer-by-layer self-assembly ( $\mathrm{LbL}$ ) technology to modify them to have antibacterial ability. Surface morphology and composition analyses of the cell-compatible LbL structural film confirmed successful deposition. The wet tensile modulus of the film increased from 2.16 MPa (pure silk fibroin film) to $4.89 \mathrm{Mpa}$ [48]. Using freeze induced assembly and hot-pressing methods, Chen et al. [49] toughened and modified delignificated nano-cellulose (DNLC) by the synergistic effect of CS and $\mathrm{MoS}_{2}$ and prepared the high-performance ternary lignocellulose nacres. Additionally, Almeida et al. [50] proposed multifunctional (MF) CS/hyaluronic acid (HA) LbL films developed by the dipcoating technology. They alternately combined the inorganic nanoparticles and bioactive glass nanoparticles (BGNP) with catechol-functionalized biopolymeric layers CS and HA to obtain MF films, which could be used in bone tissue engineering because of their ability to create an environment compatible with osteogenesis (Figure 6). Abba et al. [51] used CS as the matrix material (mortar) and alumina sheets as the reinforcing particles (brick) to prepare the nacreous microstructured mixed film material. The effects of inorganic to 
organic matter ratios and relative humidity on mechanical properties were studied. The results showed that the relative humidity of the environment had a significant effect on the measured mechanical properties. Yao et al. [46] prepared brick-and-mortar CS-layered dihydroxide hybrid films by sequential dipping coating and LbL technology, which had high mechanical properties and tensile strength of $160 \mathrm{MPa}$ (higher than that of natural brick-and-mortar films). Subsequently, they developed a novel approach for manufacturing CS-montmorillonite (MTM) biomimetic composite membranes with a self-assembly method caused by vacuum filtration or water evaporation. The hybridized CS-MTM building blocks were arranged into a pearl layered structure composite material. The film had high performance in terms of mechanical properties, light transmittance, and fire resistance [52].

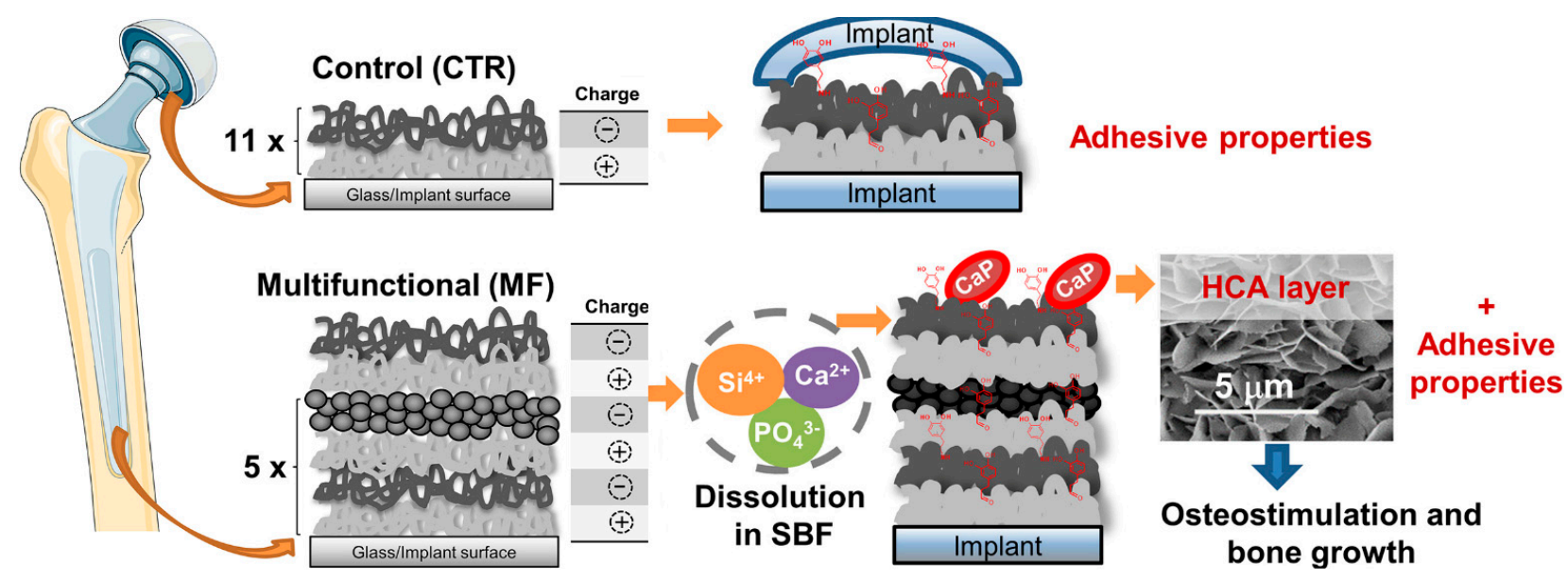

Figure 6. Schematic illustration of the different multifunctional (MF) and control (CTR) LbL coatings (11×: the number of repetitions required for the CTR group to alternately immerse the substrate in the oppositely-charged polyelectrolyte solutions to produce LbL coatings with 11 bilayers, i.e., 22 layers; $5 \times$ : the number of repetitions required for the MF group to alternately immerse the substrate in the oppositely-charged polyelectrolyte solutions to produce LbL coatings with 22 layers). Reproduced with permission from [50], Copyrighter Elsevier 2020.

\subsubsection{Nanocoatings and Other Composite Material}

Using carboxymethyl CS (CCS) and MMT, Xie et al. [53] fabricated super-efficiency fire-safe nanocoating via one-step self-assembly, which showed well-arranged nacre-like microstructure and high transparency. Fang et al. demonstrated a convenient approach to fabricate a nacre-mimetic flame-retardant system by the LbL method using MMT as matrix and CS as mortar to simulate the structure of the nacreous layer. The prepared paper had excellent flame retardant properties [54]. It is noteworthy that visualization of the injured tissue may allow prompt and appropriate wound care in burn-injured patients. Based on the previous reports [94], Saito et al. [55] loaded antibiotics (tetracycline, TC) on nanosheets and developed TC nanosheets with high transparency and fluorescence that could help monitor burn care management (Figure 7). The prepared TC-nanosheet was composed of three layers (LbL/TC/PVAc): LbL made of CS and sodium alginate (SA) as a bottom layer, $\mathrm{TC}$ as an antibiotic layer, and poly(vinyl acetate) as a hydrophobic barrier layer. 


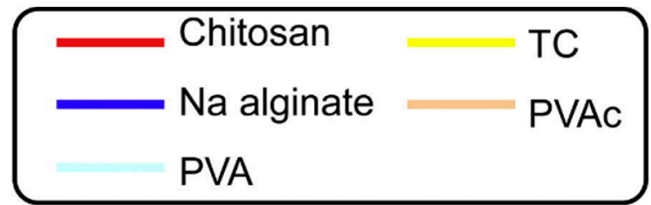

(i)

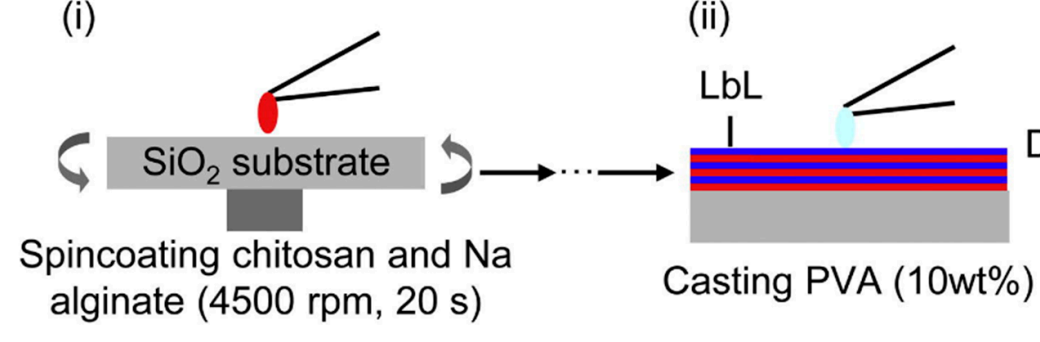

(ii)

(iv)

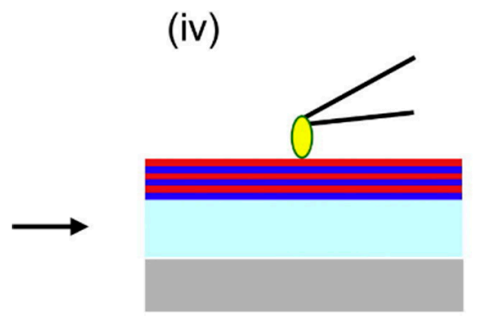

Deposition of a TC solution
( $v)$
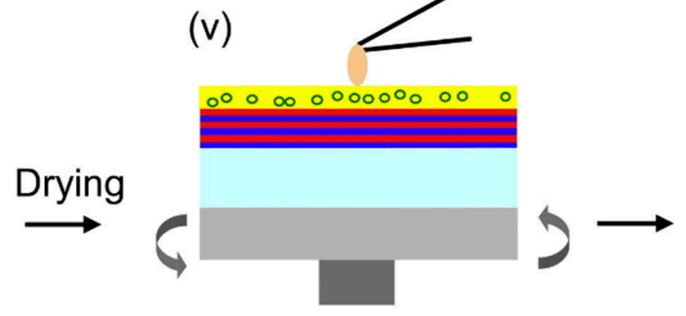

Spincoating PVAC (4000 rpm, $20 \mathrm{~s}$ ) (iii)

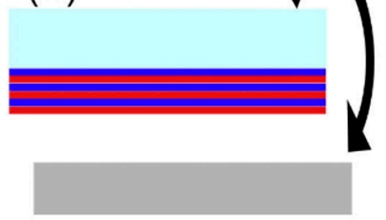

Peeling off and reversing a nanosheet
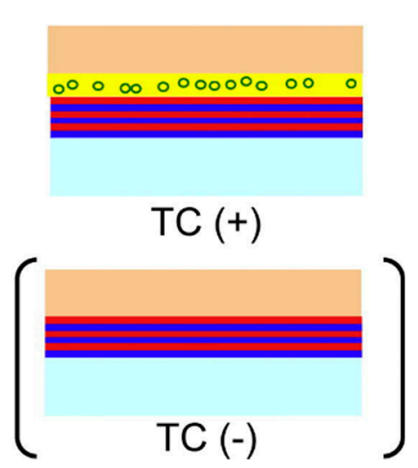

Figure 7. Preparation scheme for TC-loaded nanosheets. (i) Chitosan and sodium alginate were alternately spin coated. (ii) PVA was cast onto the LbL nanosheet. (iii) After drying PVA as a supporting layer, the nanosheet was peeled off with PVA and reversed onto the substrate. (iv) TC solution deposited on nanosheet. (v) After drying to make a TC layer, PVAc was spin coated onto the new layer. Reproduced with permission from [55], Copyrighter Elsevier 2012.

The versatile technique used to construct the antibiotic-loaded nanosheets is applicable to other drugs with appropriate solubility with that of membrane components. Based on the principle of bio-adhesion/anti-adhesion, Yuan et al. [56] developed an organ-like biological coating chip with self-repair and antioxidant functions through LbL self-assembly, which was used for cell sorting, capture, and on-demand release. In this work, two coatings with opposite functions on enhancing cell adhesion coatings were fabricated. Adherentenhancing coatings (CROD coatings) were prepared from oxidized alginate grafted with carboxymethyl CS modified with RGD polypeptides, and an anti-adhesion coating (PANM coatings) was prepared mainly from 2-methylacrylloxyethyl phosphorycholine (MPC). Metal ions were introduced into the artificial nacre to form new chemical bonds and reinforce the interface interaction. Chen et al. systematically studied the influence of different metal ions on the binary system. It was found that different metal ions with various sizes and charges would affect machine performances. Through the introduction of $\mathrm{Mg}^{2+}$, the strength and toughness of MTM-CS ternary artificial nacre could reach $200 \mathrm{MPa}$ and $40 \mathrm{MJ} \mathrm{m}^{-3}$, respectively, and its toughness was 20 times that of natural nacre [57]. Combining the layered structure of brick-and-mortar and the biological mineralization process, Zhang et al. [66] constructed a hydroxyapatite/CS (HA/CH)-layered composite material to remove heavy metal $\mathrm{Pb}$ (II) from continuous flowing wastewater. The composite material contained a microstructure similar to a plate tower; large pores between layers facilitated the transfer of continuous flowing wastewater and the separation of adsorbent and water. Ruan et al. designed an organic matrix composed of CS and cisbutenediolic acid (maleic acid, MAc) to simulate the function of a nacreous matrix and then generated a layered montmorillonite matrix of composite materials. Hydroxyapatite with a multiscale hierarchical structure was synthesized using layered montmorillonite-CS composites as precursors via a topotactic phase transformation process [67]. 


\section{Imitation Extracellular Matrix Material}

The extracellular matrix (ECM) is important for guiding cellular development and maintaining the desired phenotype. It is both the structural basis of cells and the source of three-dimensional biochemical and biophysical signals that trigger and regulate cell behavior [95-98].

\subsection{Functional Cell Micro-Environment Material}

Materials that can imitate the shape and function of natural ECM in vivo are being developed for in vitro research in the field of cell micro-environment engineering [99-102]. Construction of functional tissues relies on the structural environment, cell-biomaterial interactions, and incorporated biological signals [103]. In this sense, hydrogels can easily adjust their physico-chemical (electrical charge and pore size) [104] and mechanical properties [105], which natively lead to cellular function. María et al. combined a hydrogel backbone network composed of CS and hyaluronic acid with a terpolymer containing catechol; this hybrid system had the advantage of the two polymers crosslinked with Fe to form an interpermeable polymer network (IPN). When used as a wound dressing, this IPN can constitute an ECM simulation platform with high cell affinity and bioactivity. Combined with the controlled release of catechin, it promoted the tissue regeneration process and contributed to wound healing [42]. Ewa et al. [68] modified the surface of CS fibers with fragments of human collagen I (10-15 amino acids) by physical (water absorption during electrospraying) and chemical (amide and peptide groups) activities to obtain a complex of glycosaminoglycans (GAG) and peptides similar to those present in the cell matrix (Figure 8). Subsequently, the effect of different modification methods on the fiber was evaluated. Compared with physical modification, the results showed that the chemical modification made the peptide evenly distributed on the fiber without changing its shape. To promote the development of organ-on-a-chip and other physiologically-relevant biomembrane fields, Rosella et al. [43] presented a microfluidic platform for the synthesis of biomembranes during gelation and studied its role as an extracellular matrix support. High-throughput studies on biomembranes were prepared with different biopolymer materials to characterize the relationship between the different conditions imposed on them, thereby revealing their biological application potential.

\subsection{Bone Tissue Engineering Material}

Orthopedic biomaterials or coatings with ECM-like nano-features can induce ideal interactions between bone tissue and the implant surface. CS-gelatin $(\mathrm{G})$ composite materials have promising bone tissue engineering possibilities because they combine the cellular adhesion of $\mathrm{G}$ with the antibacterial properties of CS [106-108]. Altuntas et al. [58] prepared nanocrystalline CS:G films with ordered nanopore arrays that were developed using anodic alumina molds via a drop-casting approach. Experiments demonstrated that these nanopillared films had good bactericidal properties and the ability to induce early osteogenic differentiation, making them a promising antibacterial coating material for planting. Tangprasert et al. prepared a gelatin/CS/compounded calcium phosphate (Gel:CS:CCP) hydrogel to simulate the extracellular matrix of calcified soft tissues and then designed an ex-vivo model for evaluating tissue formation. The results showed that the molecular structure and morphology of the self-organized hydrogel in Gel: CS: CCP (1:1:0.1) was similar to the extracellular matrix formed by in-situ bone. Its physical and biological properties enhanced cell viability and proliferation [44]. It was speculated that the remarkable characteristics of CS and the ability of graphene oxide (GO) to refine and repair major bone defects could induce and support bone tissue formation. To promote one novel scaffold based on a natural compound of CS and GO, Dinescu et al. [22] explored the potential of a new scaffold for tissue engineering applications and regenerative medicine. Drawing lessons from the necessary support structure for tendon regeneration, Sundaram et al. presented a CS hydrogel scaffold reinforced with a twisted poly(L-lactic acid) aligned microfibrous bundle to mimic tendon extracellular matrix [23]. De Witte et al. [24] fabri- 
cated a biodegradable, osteoconductive, porous chitosan scaffold via the freeze-drying method, synthesized poly(methyl methacrylate-co-methacrylic acid) nanoparticles, and immobilized to the scaffold via carbodiimide-crosslinker chemistry. Fluorescence imaging results showed that the nanoparticles were wholly retained in the scaffold for up to 4 weeks, had good biocompatibility, and did not negatively affect human umbilical vein endothelial cells (Figure 9). To find effective bone tissue regeneration materials based on mesenchymal stem cells, Zhao et al. [45] developed an injectable or bio-printed carboxymethyl chitosan $(\mathrm{CMCh})$ and amorphous calcium phosphate $(\mathrm{ACP})$ composite NP hydrogel (designated $\mathrm{CMCh}-\mathrm{ACP}$ hydrogel). It was the first to demonstrate that $\mathrm{pH}$ changes can be used to control the assembly of polymer-stabilized ACP NPs to form elastic hydrogels. Their findings strongly suggested that $\mathrm{CMCh}-\mathrm{ACP}$ hydrogels may be developed into novel scaffolds for stem-cell-based bone tissue engineering.

a) Electrospinning
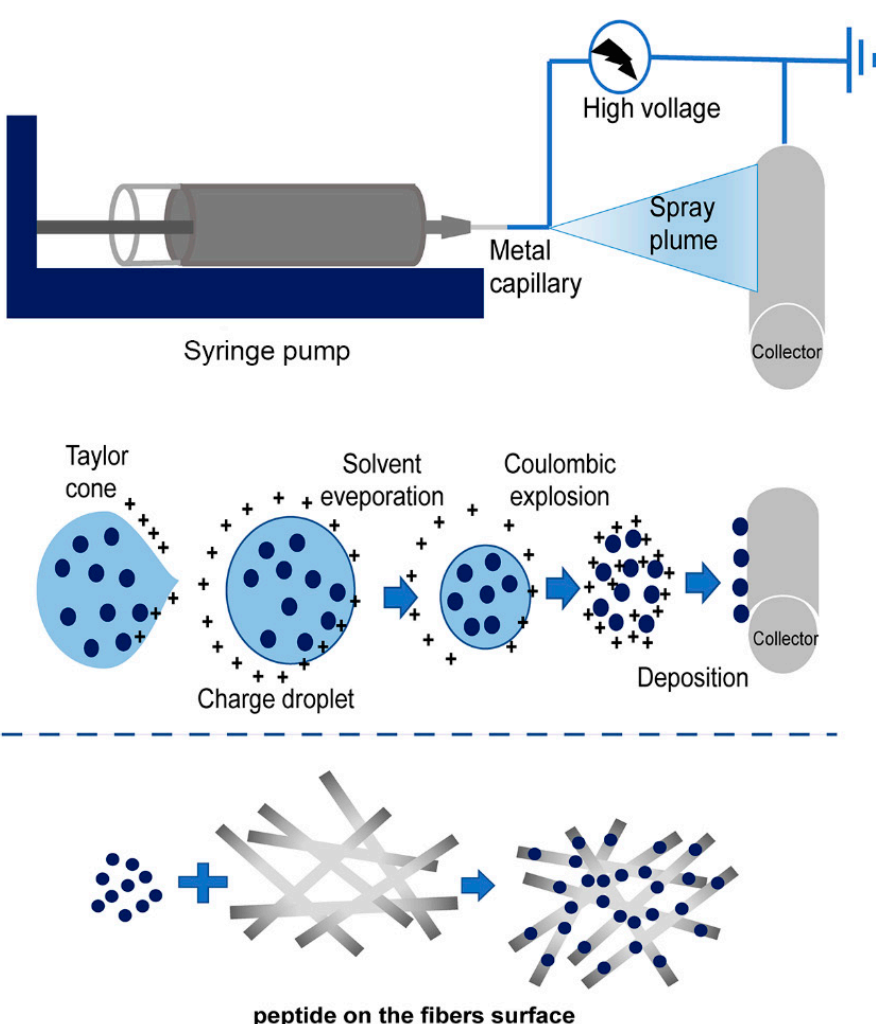

peptide on the fibers surface b) Selected fragments Equimolae mixture of superactive triazine of collagen I esters of selected fragments of collagens I

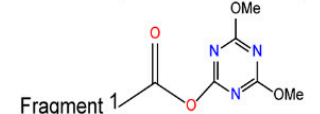

Fragment 1 Fragment 1

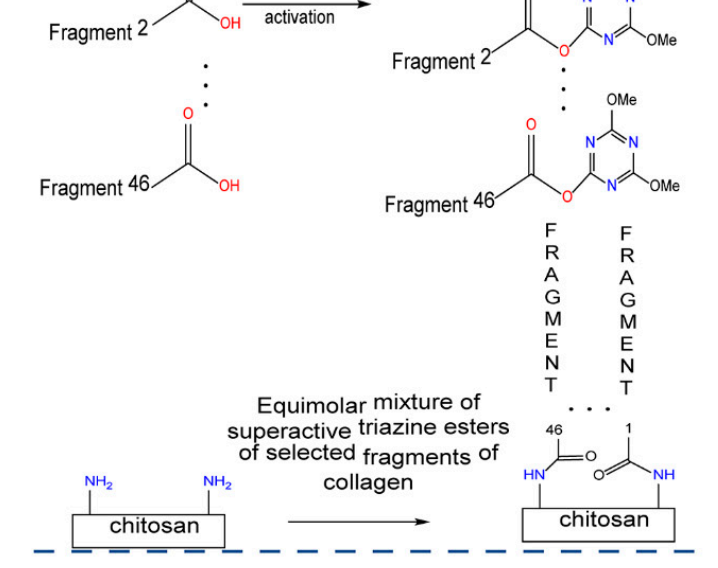
Fragment 46<smiles></smiles>

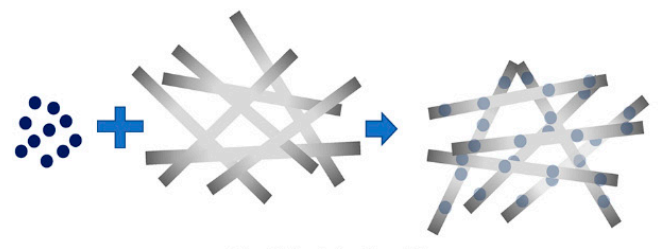

Peptide into the fibers

Figure 8. Scheme of applied modification methods of fibrous chitosan substrates: Physical (a) electrospinning was used to apply the solution of human collagen I fragments to the CS non-woven fabric through the potential difference between the nozzle and the collector. The resulting CS with physically embedded fragments of human collagen I (CS/F K1) were fixed using lyophilization. Chemical (b), the coupling reagent, and NMM were added into the peptides solution to activate the peptide, and the non-woven sheet of CS was immersed in the solution containing active peptides to complete the reaction. After washing and drying, the covalent link fragment of the non-woven sheet of CS and human collagen I (CS/C K1) was obtained. Reproduced with permission from [68], Copyrighter Elsevier 2020. 


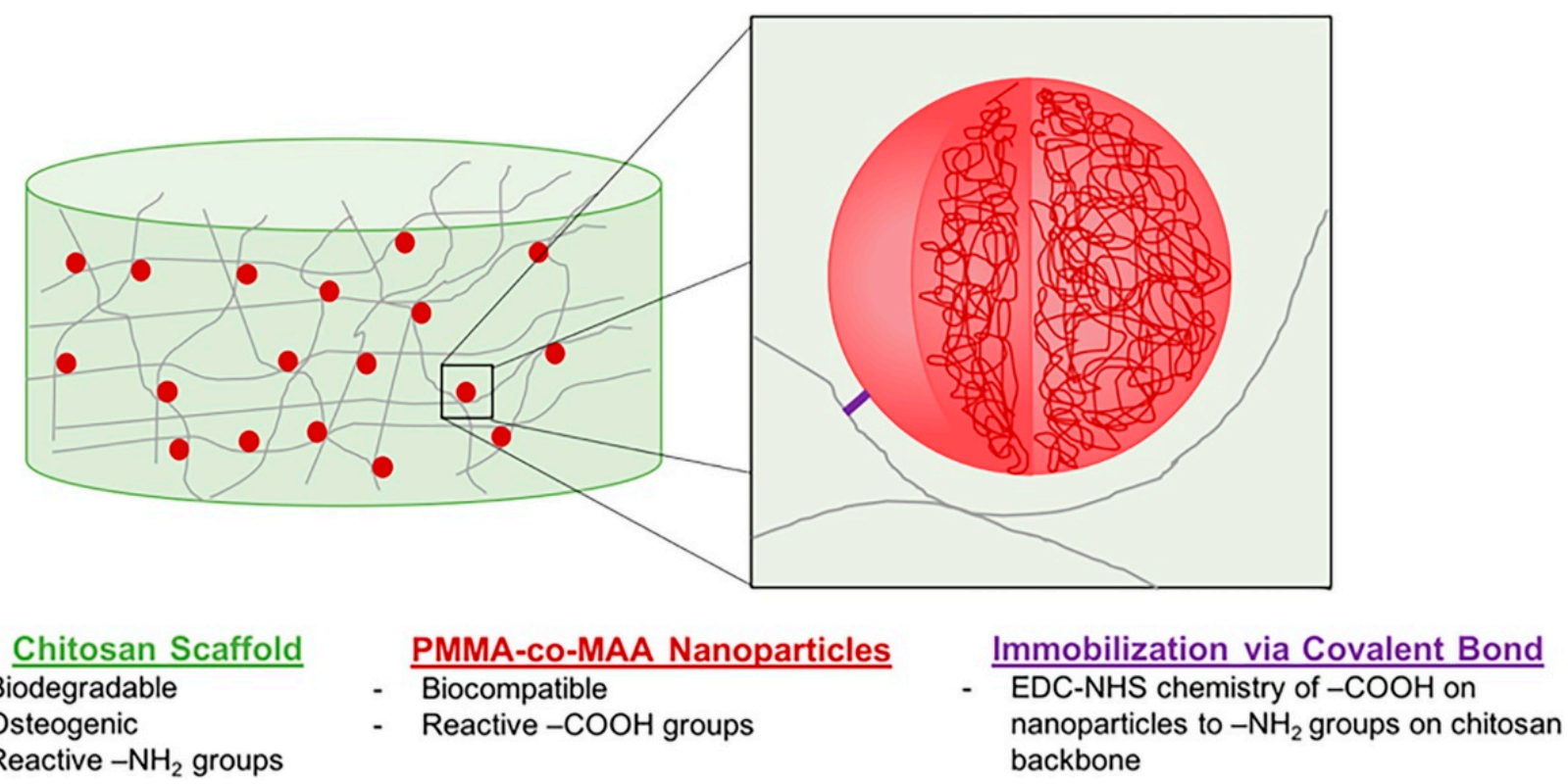

- Osteogenic

- Reactive $-\mathrm{NH}_{2}$ groups

- Biocompatible

Reactive $-\mathrm{COOH}$ groups

Figure 9. Design of a two-phase NP-scaffold system relying on the immobilization of P(MMA-co-MAA) NPs to a CS scaffold backbone for the sustained delivery of growth factors in bone tissue engineering applications. Reproduced with permission from [24], Copyrighter Wiley 2020.

\section{Imitation Desert Beetle Material}

The Namib desert beetle can collect drinking water from fog-laden wind. This is because the insect's bumpy surface alternates between waxy hydrophobic concave areas and non-waxy hydrophilic convex areas. The unique wettability of this pattern allows it to capture and coalescence tiny water droplets in the fog in the hydrophilic bulge area, then to the hydrophobic smooth area, and finally to the insect's mouth [109-113]. Combining these characteristics with the advantages of polyvinylidene fluoride and CS, Al-Gharabli et al. [59] achieved better separation performance of hybrid materials by adopting the method of "grafting". The silicon alkyl modifier was used to fix CS on the surface of the porous structure and internally. Hydrophilic CS can improve the permeability of the membrane, imbue antifouling properties, and broaden the application range of the new materials. This is the first example of a chemical combination of CS with active polyvinylidene fluoride materials (Figure 10). 


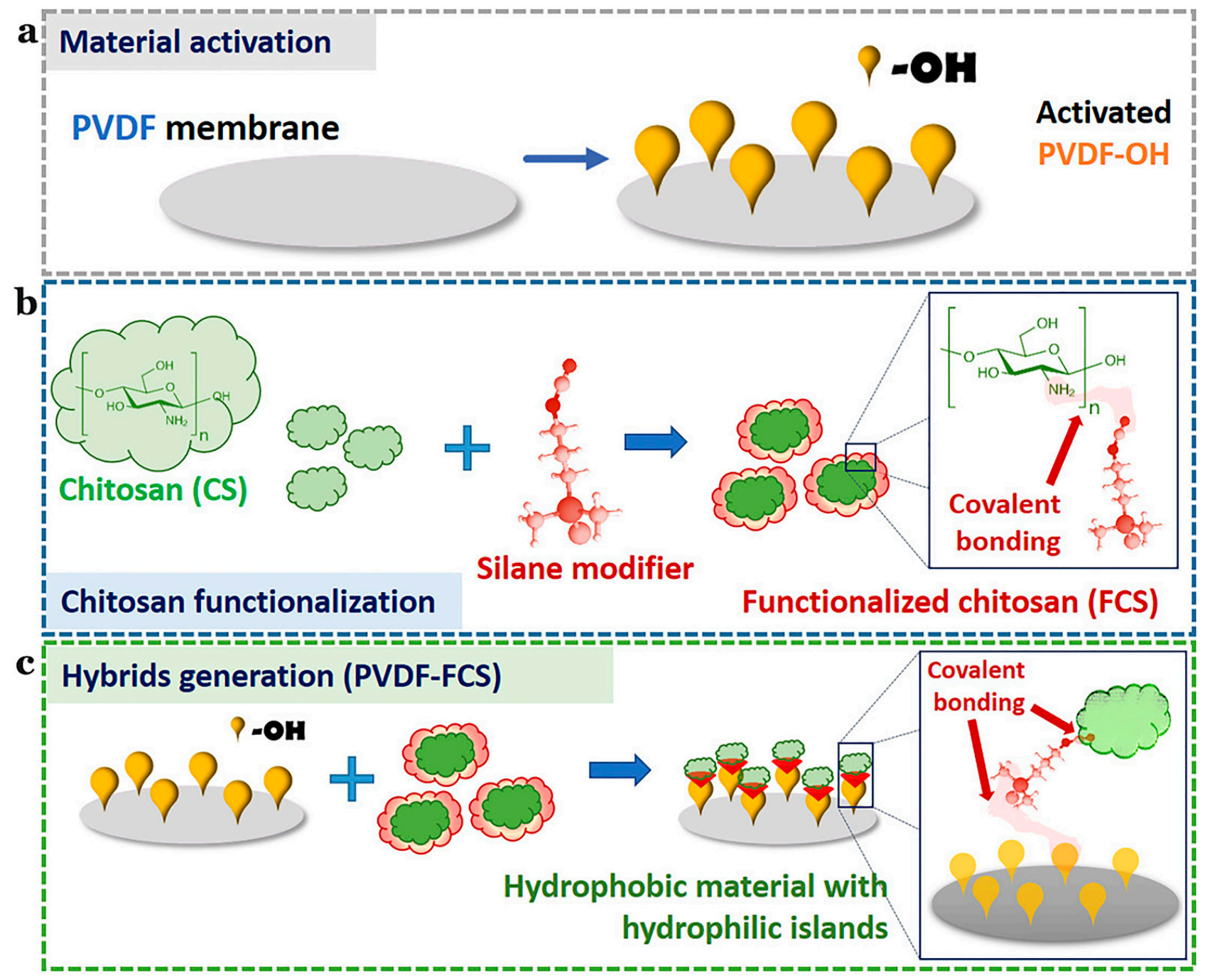

Figure 10. Schematic illustration of the preparation of PVDF-FCS. (a) The reaction for chitosan functionalization. (b) CS was anchored to pre-activated PVDF membranes by urea linker via salinization. (c) The generation of the hybrid materials. Reproduced with permission from [59], Copyrighter Elsevier 2020.

\section{Imitation Honeycomb Structure Material}

Based on indepth research into biomimetic material preparation and application, the honeycomb structure with the most tightly filled hexagonal holes in nature inspired to manufacture controllable micro-structure materials. Yu et al. [114] developed massively manufactured bionic polymer wood with a controllable honeycomb microstructure by combining traditional resin self-assembly and thermal curing. On this basis, Zhang et al. [60] prepared a new ceramic/polymer composite with honeycomb structure using CS and Poly(ethylene glycol) diglycidyl ether as precursors with a freezing casting method. The honeycomb structure effectively reduced steric hindrance between the material and glycopeptide (Figure 11). Three-dimensional honeycomb porous carbon has excellent mechanical properties and a particular surface area. Dai et al. exploited this property to prepare three-dimensional CS/honeycomb porous carbon/hydroxyapatite composite material. The synthesized composite scaffold had high porosity and specific mechanical strength similar to bone tissue and could promote osteogenesis [25]. To further expand the application potential of CS, Guo et al. [69] used it as the only combined source of carbon and nitrogen to controllably prepare an inherent nitrogen-doped honeycomb-like carbon $/ \mathrm{Fe}_{3} \mathrm{O}_{4}$ composite material with favorable versatility. Notably, CS can spontaneously form a porous honeycomb-like structure after gelation and carbonization, so the composite material exhibited good mi- 
crowave absorption properties. It also showed good ability to adsorb toxic metal ions $\mathrm{Cr}(\mathrm{VI})$ and degrade water organic pollutants. Deng et al. reported nitrogen-containing CS-based porous carbon microspheres (CPCM) with a honeycomb-like porous structure and a unique spherical morphology. The feasible step-by-step strategy proposed by the group under the conditions of $\mathrm{HCl}$ and $\mathrm{KOH}$ enabled the material's structure to be precisely adjusted. It was also a promising reusable adsorbent with a high regenerative capacity [70]. Zhu et al. [71] prepared aminomethylphosphonic acid (AMPA) chelated cross-linked CS $\left(\mathrm{CTSM} @ \mathrm{AMPA}-\mathrm{Ti}^{4+}\right.$ ) composites with stable structure, low steric hindrance, and high $\mathrm{Ti}^{4+}$ loading. The material showed excellent selectivity and sensitivity to phosphopeptides and dimensional hindrance, which could be used as a promising adsorbent for the enrichment of phosphopeptides. To alleviate the increasingly severe environmental problems, Zou et al. [72] reported a novel eco-friendly material with high thermal conductivity and a honeycomb-like structure, which was composited by using the significant difference in scales between the CS microspheres (CSM) and the hydroxyl-functionalized hexagonal boron nitide (OH-BN) nanosheets. The novel heat-conduction materials were degradable, quick to recycle, and had a broad market prospect.

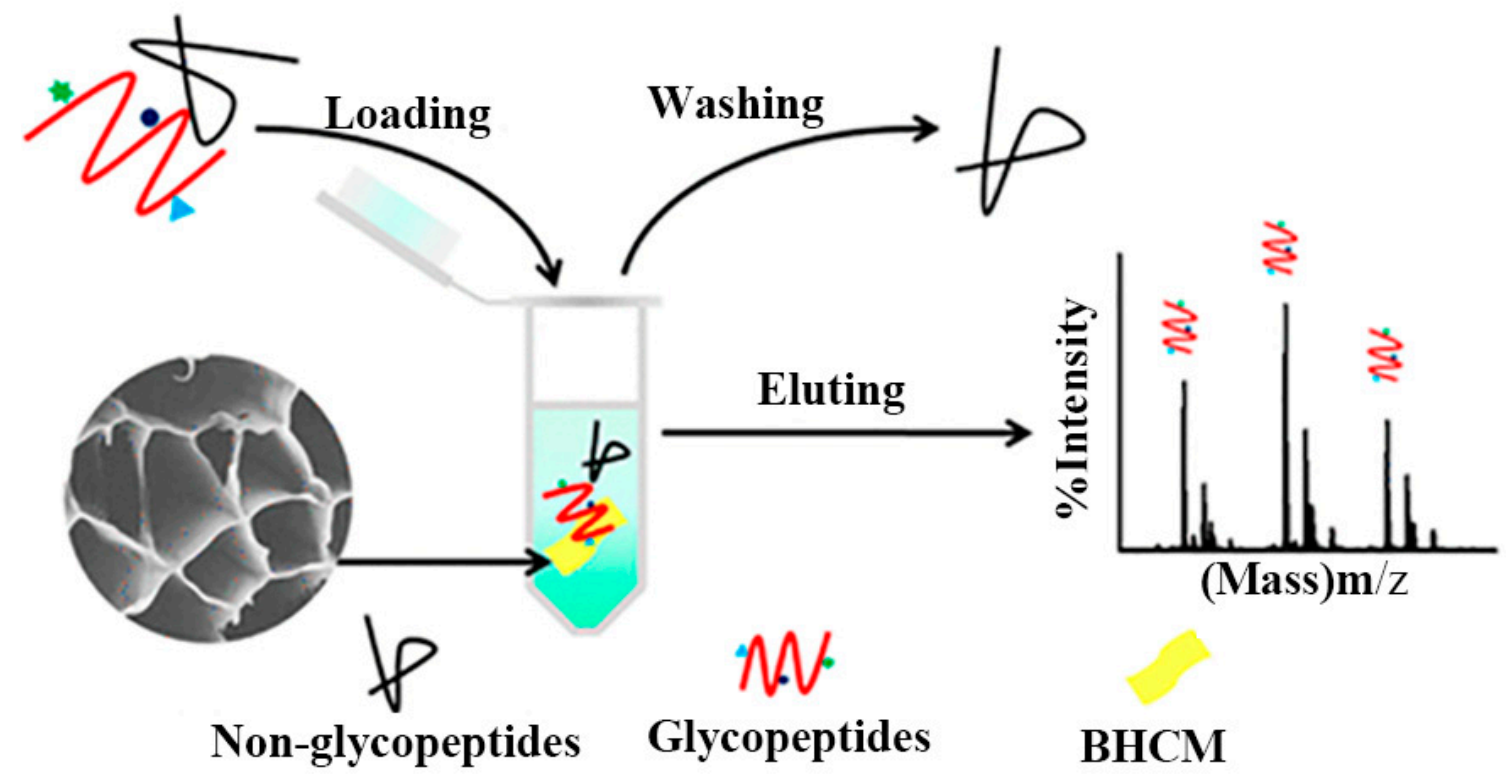

Figure 11. Schematic diagram of honeycomb-shaped macroporous bionic honeycomb chitosan film preparation with a freezing casting method. Reproduced with permission from [60], Copyrighter ACS publications 2019.

\section{Conclusions}

In this paper, the chitosan-based biomimetic materials based on the biological characteristics of bivalves, cell matrices, desert beetles, and honeycomb structure of bees were reviewed. Various forms of biomimetic functional materials (scaffolds, gels, films, and others) based on chitosan have promising applications in the fields of biomedical and adsorptive materials, but many challenges remain in this area. On the one hand, the functional mechanism of some organisms has not yet been fully understood. For example, the biomineralization mechanism of mollusks, such as shellfish, is not yet clear, and bionics is still in its preliminary stages. On the other hand, the long-term biosafety of the prepared materials is not yet clear, for example, whether the retention of the prepared materials loaded with growth factors or drugs will pose a risk to normal tissue growth. Based on the good biological properties and easy modification of chitosan, we believe that a better understanding of the functional mechanisms and safety of the materials involved in the above mentioned organisms, as well as the development of bionics, will greatly benefit the design of intelligent and biosecurity chitosan-based biomimetic materials. We expect that 
this review will be truly beneficial to the work of aspiring researchers in the field of CS bionics and its related applications.

Author Contributions: Methodology, conceptualization, and writing—original draft preparation, Z.Z.; validation and writing-review and editing, L.Z. and C.L.; revision and editing, X.X., G.L. and S.L.; conceptualization, funding acquisition, project administration, and writing-review and editing, Z.H. All authors have read and agreed to the published version of the manuscript.

Funding: This research was funded by Project of Science and Technology Plan of Zhanjiang (2019A01017 and 2020A01026), National College Student Innovation and Entrepreneurship Training Program of Guangdong Ocean University (202010566032), and Guangdong Ocean University Undergraduate Innovation Team Project (CXTD2021020).

Institutional Review Board Statement: Not applicable.

Data Availability Statement: Not applicable.

Acknowledgments: The authors acknowledge the financial supports from Project of Science and Technology Plan of Zhanjiang (2019A01017 and 2020A01026), National College Student Innovation and Entrepreneurship Training Program of Guangdong Ocean University (202010566032), and Guangdong Ocean University Undergraduate Innovation Team Project (CXTD2021020).

Conflicts of Interest: The authors declare no conflict of interest.

\section{References}

1. Klinger, C.; Żółtowska, S.; Wysokowski, M.; Tsurkan, M.; Galli, R.; Petrenko, I.; Machałowski, T.; Ereskovsky, A.; Martinović, R.; Muzychka, L.; et al. Express method for isolation of ready-to-use 3D chitin scaffolds from Aplysina archeri (Aplysineidae: Verongiida) Demosponge. Mar. Drugs 2019, 17, 131. [CrossRef]

2. Machaowski, T.; Wysokowski, M.; Tsurkan, M.V.; Galli, R.; Schimpf, C.; Rafaja, D.; Brendler, E.; Viehweger, C.; ŻółtowskaAksamitowska, S.; Petrenko, I.; et al. Spider chitin: An ultrafast microwave-assisted method for chitin isolation from Caribena versicolor spider molt cuticle. Molecules 2019, 24, 3736. [CrossRef] [PubMed]

3. Anitha, A.; Sowmya, S.; Kumar, P.; Deepthi, S.; Jayakumar, R. Chitin and chitosan in selected biomedical applications. Prog. Polym. Sci. 2014, 39, 1644-1667. [CrossRef]

4. Jeon, Y.J.; Shahidi, F.; Arachchi, J.K.V. Food applications of chitin and chitosans. Trends Food Sci. Technol. 1999, $10,37-51$.

5. Mittal, H.; Ray, S.S.; Kaur, S.B.; Kaur, B.J.; Sharma, J.S.; Alhassan, S.M. Recent progress in the structural modification of chitosan for applications in diversified biomedical fields. Eur. Polym. J. 2018, 109, 402-434. [CrossRef]

6. Nowacki, K.; Stępniak, I.; Machałowski, T.; Wysokowski, M.; Petrenko, I.; Schimpf, C.; Rafaja, D.; Langer, E.; Richter, A.; Ziętek, J.; et al. Electrochemical method for isolation of chitinous 3D scaffolds from cultivated Aplysina aerophoba marine demosponge and its biomimetic application. Appl. Phys. A 2020, 126, 368. [CrossRef]

7. Tsurkan, M.V.; Voronkina, A.; Khrunyk, Y.; Wysokowski, M.; Petrenko, I.; Ehrlich, H. Progress in chitin analytics. Carbohydr. Polym. 2021, 252, 117204. [CrossRef]

8. Machałowski, T.; Rusak, A.; Wiatrak, B.; Haczkiewicz-Leśniak, K.; Popiel, A.; Jaroszewicz, J.; Żak, A.; Podhorska-Okołów, M.; Jesionowski, T. Naturally formed chitinous skeleton isolated from the marine demosponge Aplysina fistularis as a 3D scaffold for tissue engineering. Materials 2021, 14, 2992. [CrossRef]

9. Negm, N.A.; Hefni, H.H.; Abd-Elaal, A.A.; Badr, E.A.; Kana, M.T.A. Advancement on modification of chitosan biopolymer and its potential applications. Int. J. Biol. Macromol. 2020, 152, 681-702. [CrossRef]

10. Shou, Y.F.; Zhang, J.H.; Yan, S.F.; Xia, P.F.; Xu, P.L.; Li, G.F.; Zhang, K.X.; Yin, J.B. Thermoresponsive Chitosan/DOPA-Based Hydrogel as an Injectable Therapy Approach for Tissue-Adhesion and Hemostasis. ACS Biomater. Sci. Eng. 2020, 6, 3619-3629. [CrossRef]

11. Rusu, A.G.; Chiriac, A.P.; Nita, L.E.; Irina, R.; Pinteala, M.; Tartau, L. Chitosan Derivatives in Macromolecular Co-assembly Nanogels with Potential for Biomedical Applications. Biomacromolecules 2020, 21, 4231-4243. [CrossRef]

12. Gavhane, Y.N.; Atul, S.G.; Adhikrao, V.Y. Chitosan and Its Applications: A Review of Literature. Int. J. Res. Pharm. Biomed. Sci. 2013, 4, 312-332.

13. Hadidi, M.; Pouramin, S.; Adinepour, F.; Haghani, S.; Jafari, S.M. Chitosan nanoparticles loaded with clove essential oil: Characterization, antioxidant and antibacterial activities. Carbohydr. Polym. 2020, 236, 116075. [CrossRef] [PubMed]

14. Sahariah, P.; Másson, M. Antimicrobial Chitosan and Chitosan Derivatives: A Review of the Structure-Activity Relationship. Biomacromolecules 2017, 18, 3846-3868. [CrossRef] [PubMed]

15. Naik, R.R.; Singamaneni, S. Introduction: Bioinspired and Biomimetic Materials. Chem. Rev. 2017, 117, 12581-12583. [CrossRef]

16. Zhao, Q.L.; Wang, Y.L.; Cui, H.Q.; Du, X.M. Bio-inspired sensing and actuating materials. J. Mater. Chem. C 2019, 7, 6493-6511. [CrossRef] 
17. Liu, Z.Q.; Meyers, M.A.; Zhang, Z.F.; Ritchie, R.O. Functional gradients and heterogeneities in biological materials: Design principles, functions, and bioinspired applications. Prog. Mater. Sci. 2017, 88, 467-498. [CrossRef]

18. Green, D.; Walsh, D.; Mann, S.; Oreffo, R.O.C. The potential of biomimesis in bone tissue engineering: Lessons from the design and synthesis of invertebrate skeletons. Bone 2002, 30, 810-815. [CrossRef]

19. Mano, J.F. Biomimetic Approaches for Biomaterials. Development 3; John Wiley \& Sons: New York, NY, USA, 2013.

20. Chen, X.Y.; Zhao, X.; Wang, G.X. Review on marine carbohydrate-based gold nanoparticles represented by alginate and chitosan for biomedical application. Carbohydr. Polym. 2020, 244, 116311. [CrossRef]

21. Li, X.; Yin, H.M.; Su, K.; Zheng, G.S.; Mao, C.Y.; Wang, P.; Zhang, Z.; Xu, J.Z.; Zhong, G.J.; Liao, G.Q. Polydopamine-Assisted Anchor of Chitosan onto Porous Composite Scaffolds for Accelerating Bone Regeneration. ACS Biomater. Sci. Eng. 2019, 5 , 2998-3006. [CrossRef]

22. Dinescu, S.; Ionita, M.; Ignat, S.R.; Costache, M.; Hermenean, A. Graphene Oxide Enhances Chitosan-Based 3D Scaffold Properties for Bone Tissue Engineering. Int. J. Mol. Sci. 2019, 20, 5077. [CrossRef]

23. Sundaram, M.N.; Deepthi, S.; Mony, U.; Shalumon, K.T.; Jayakumar, R. Chitosan hydrogel scaffold reinforced with twisted poly (L lactic acid) aligned microfibrous bundle to mimic tendon extracellular matrix. Int. J. Biol. Macromol. 2018, 122, 37-44. [CrossRef] [PubMed]

24. De Witte, T.M.; Wagner, A.M.; Fratila-Apachitei, L.E.; Zadpoor, A.A.; Peppas, N.A. Immobilization of nanocarriers within a porous chitosan scaffold for the sustained delivery of growth factors in bone tissue engineering applications. J. Biomed. Mater. Res. A 2020, 108, 1122-1135. [CrossRef]

25. Dai, C.B.; Li, Y.; Pan, W.Z.; Wang, G.Q.; Huang, R.Q.; Bu, Y.Y.; Liao, X.J.; Guo, K.J.; Gao, F.L. Three-Dimensional High Porosity Chitosan/Honeycomb Porous Carbon/Hydroxyapatite Scaffold with Enhanced Osteoinductivity for Bone Regeneration. ACS Biomater. Sci. Eng. 2019, 6, 575-586. [CrossRef] [PubMed]

26. Shin, M.; Park, S.G.; Oh, B.C.; Kim, K.; Jo, S.; Lee, M.S.; Oh, S.S.; Hong, S.H.; Shin, E.C.; Kim, K.-S.; et al. Complete prevention of blood loss with self-sealing haemostatic needles. Nat. Mater. 2017, 16, 147-152. [CrossRef]

27. Han, W.; Zhou, B.; Yang, K.; Xiong, X.; Luan, S.F.; Wang, Y.; Xu, Z.; Lei, P.; Luo, Z.S.; Gao, J.; et al. Biofilm-inspired adhesive and antibacterial hydrogel with tough tissue integration performance for sealing hemostasis and wound healing. Bioact. Mater. 2020, 5, 768-778. [CrossRef]

28. Zhang, X.; Sun, G.H.; Tian, M.P.; Wang, Y.N.; Qu, C.C.; Cheng, X.J.; Feng, C.; Chen, X.G. Mussel-inspired antibacterial polydopamine/chitosan/temperature-responsive hydrogels for rapid hemostasis. Int. J. Biol. Macromol. 2019, 138, 312-333. [CrossRef] [PubMed]

29. Han, L.; Li, P.F.; Tang, P.F.; Wang, X.; Zhou, T.; Wang, K.F.; Ren, F.Z.; Guo, T.L.; Lu, X. Mussel-inspired cryogels for promoting wound regeneration through photobiostimulation, modulating inflammatory responses and suppressing bacterial invasion. Nanoscale 2019, 11, 15846-15861. [CrossRef] [PubMed]

30. Kim, K.; Kim, K.; Ryu, J.H.; Lee, H. Chitosan-catechol: A polymer with long-lasting mucoadhesive properties. Biomaterials 2015, 52, 161-170. [CrossRef]

31. Ryu, J.H.; Choi, J.S.; Park, E.; Min, R.E.; Seongyeon, J.; Lee, M.S.; Kwon, S.K.; Lee, H. Chitosan oral patches inspired by mussel adhesion. J. Control. Release 2020, 317, 57-66. [CrossRef]

32. Zeng, Z.W.; Liu, D.H.; Li, D.J.; Mo, X.M. An injectable double cross-linked hydrogel adhesive inspired by synergistic effects of mussel foot proteins for biomedical application. Colloids Surf. B 2021, 204, 111782. [CrossRef]

33. He, X.Y.; Sun, A.; Li, T.; Qian, Y.J.; Qian, Z. Mussel-inspired antimicrobial gelatin/chitosan tissue adhesive rapidly activated in situ by h2o2/ascorbic acid for infected wound closure. Carbohydr. Polym. 2020, 247, 116692. [CrossRef]

34. Ryu, J.H.; Lee, Y.; Kong, W.H.; Kim, T.G.; Park, T.G.; Lee, H. Catechol-Functionalized Chitosan/Pluronic Hydrogels for Tissue Adhesives and Hemostatic Materials. Biomacromolecules 2011, 12, 2653-2659. [CrossRef]

35. Park, E.; Lee, J.; Huh, K.M.; Lee, S.H.; Lee, H. Toxicity-Attenuated Glycol Chitosan Adhesive Inspired by Mussel Adhesion Mechanisms. Adv. Healthc. Mater. 2019, 8, 1900275. [CrossRef]

36. Kim, J.N.; Lee, J.H.; Lee, H.S.; Oh, I.K. Stretchable and self-healable catechol-chitosan-diatom hydrogel for triboelectric generator and self-powered tremor sensor targeting at parkinson disease. Nano Energy 2020, 82, 105705. [CrossRef]

37. Hu, C.; Long, L.Y.; Cao, J.; Zhang, S.M.; Wang, Y.B. Dual-crosslinked mussel-inspired smart hydrogels with enhanced antibacterial and angiogenic properties for chronic infected diabetic wound treatment via ph-responsive quick cargo release. Chem. Eng. J. 2021, 411, 128564. [CrossRef]

38. Gao, G.; Jiang, Y.W.; Jia, H.R.; Wu, F.G. Near-infrared light-controllable on-demand antibiotics release using thermo-sensitive hydrogel-based drug reservoir for combating bacterial infection. Biomaterials 2018, 188, 83-95. [CrossRef] [PubMed]

39. Tian, M.P.; Zhang, A.D.; Yao, Y.X.; Chen, X.G.; Liu, Y. Mussel-inspired adhesive and polypeptide-based antibacterial thermosensitive hydroxybutyl chitosan hydrogel as bmscs 3D culture matrix for wound healing. Carbohydr. Polym. 2021, 261 , e117878. [CrossRef]

40. Zhang, D.Y.; Hu, Z.; Zhang, L.Y.; Lu, S.T.; Li, S.D. Chitosan-based thermo-sensitive hydrogel loading oyster peptides for hemostasis application. Materials 2020, 13, 5038. [CrossRef]

41. Ghadban, A.; Ahmed, A.S.; Ping, Y.; Ramos, R.; Arfin, N.; Cantaert, B.; Ramanujan, R.V.; Miserez, A. Bioinspired pH and magnetic responsive catechol-functionalized chitosan hydrogels with tunable elastic properties. Chem. Commun. 2016, 52, 697-700. [CrossRef] 
42. María, P.B.; Lorena, B.G.; Fung, S.; Kohn, J.; Blanca, V.; Julio, S.R. Bioadhesive functional hydrogels: Controlled release of catechol species with antioxidant and antiinflammatory behavior. Mater. Sci. Eng. C 2019, 105, 110040.

43. Rosella, E.; Nan, J.A.; Dmb, C.; Jga, C. A microfluidic approach for development of hybrid collagen-chitosan extracellular matrix-like membranes for on-chip cell cultures. J. Mater. Sci. Technol. 2021, 63, 54-61. [CrossRef]

44. Tangprasert, A.; Tansakul, C.; Thuaksubun, N.; Meesane, J. Mimicked extracellular matrix of calcified soft tissue based on chitosan/gelatin/compounded calcium phosphate hydrogel to design ex vivo model for heterotopic ossification. Mater. Des. 2017, 134, 486-493. [CrossRef]

45. Zhao, C.; Qazvini, N.T.; Sadati, M.; Zeng, Z.Y.; Huang, S.F.; Losada, D. A pH-triggered, self-assembled, and bioprintable hybrid hydrogel scaffold for mesenchymal stem cell based bone tissue engineering. ACS Appl. Mater. Interfaces 2019, 11, 8749-8762 [CrossRef] [PubMed]

46. Yao, H.B.; Fang, H.Y.; Tan, Z.H.; Wu, L.H.; Yu, S.H. Biologically Inspired, Strong, Transparent, and Functional Layered OrganicInorganic Hybrid Films. Angew. Chem. Int. Ed. 2010, 49, 2140-2145. [CrossRef] [PubMed]

47. Wang, J.F.; Cheng, Q.F.; Tang, Z.Y. Layered nanocomposites inspired by the structure and mechanical properties of nacre. Chem. Soc. Rev. 2012, 41, 1111-1129. [CrossRef]

48. Ma, X.; Wu, G.M.; Dai, F.F.; Li, D.; Li, H.; Zhang, L.; Deng, H.B. Chitosan/polydopamine layer by layer self-assembled silk fibroin nanofibers for biomedical applications. Carbohydr. Polym. 2021, 251, 117058. [CrossRef]

49. Chen, Y.P.; Dang, B.K.; Sun, Q.F. Synergistic toughening of bio-inspired molybdenum disulfide-chitosan lignocellulosic nacre with photocatalytic properties. Appl. Mater. Today 2020, 20, 100785. [CrossRef]

50. Almeida, A.C.; Vale, A.C.; Reis, R.L.; Alves, N.M. Bioactive and adhesive properties of multilayered coatings based on catecholfunctionalized chitosan/hyaluronic acid and bioactive glass nanoparticles. Int. J. Biol. Macromol. 2020, 157, 119-134. [CrossRef]

51. Abba, M.T.; Hunger, P.M.; Kalidindi, S.R.; Wegst, U.G.K. Nacre-like hybrid films: Structure, properties, and the effect of relative humidity. J. Mech. Behav. Biomed. Mater. 2015, 55, 140-150. [CrossRef]

52. Yao, H.B.; Tan, Z.H.; Fang, H.Y.; Yu, S.H. Artificial Nacre-like Bionanocomposite Films from the Self-Assembly of ChitosanMontmorillonite Hybrid Building Blocks. Angew. Chem. Int. Ed. 2010, 49, 10127-10131. [CrossRef] [PubMed]

53. Xie, H.L.; Lai, X.J.; Wang, Y.L.; Li, H.Q.; Zeng, X.R. A green approach to fabricating nacre-inspired nanocoating for super-efficiently fire-safe polymers via one-step self-assembly. J. Hazard. Mater. 2018, 365, 125-136. [CrossRef] [PubMed]

54. Fang, Y.C.; Liu, X.H.; Zheng, H.L.; Shang, W.C. Bio-inspired fabrication of nacre-mimetic hybrid nanocoating for eco-friendly fire-resistant precious cellulosic chinese xuan paper-Sciencedirect. Carbohydr. Polym. 2020, 235, 115782. [CrossRef] [PubMed]

55. Saito, A.; Miyazaki, H.; Fujie, T.; Ohtsubo, S.; Kinoshita, M.; Saitoh, D.; Takeoka, S. Therapeutic efficacy of an antibiotic-loaded nanosheet in a murine burn-wound infection model. Acta Biomater. 2012, 8, 2932-2940. [CrossRef] [PubMed]

56. Yuan, R.Q.; You, D.; Wang, J.R.; Chen, Z.Z.; Ge, L.Q. A self-healing, antioxidative organoid-chip for cell sorting, capture and release-on-demand. Chem. Eng. J. 2021, 417, 129182. [CrossRef]

57. Chen, K.; Ding, J.; Zhang, S.H.; Tang, X.K.; Yue, Y.H.; Guo, L. A general bioinspired, metals-based synergic cross-linking strategy toward mechanically enhanced materials. ACS Nano 2017, 11, 2835-2845. [CrossRef]

58. Altuntas, S.; Dhaliwal, H.K.; Bassous, N.J.; Radwan, A.E. Nanopillared Chitosan-Gelatin Films: A Biomimetic Approach for Improved Osteogenesis. ACS Biomater. Sci. Eng. 2019, 5, 4311-4322. [CrossRef]

59. Al-Gharabli, S.; Al-Omari, B.; Kujawski, W.; Kujawa, J. Biomimetic hybrid membranes with covalently anchored chitosanMaterial design, transport and separation. Desalination 2020, 491, 114550. [CrossRef]

60. Zhang, L.W.; Ma, S.J.; Chen, Y.; Wang, Y.; Ou, J.; Uyama, H.; Ye, M.L. Facile Fabrication of Biomimetic Chitosan Membrane with Honeycomb-Like Structure for Enrichment of Glycosylated Peptides. Anal. Chem. 2019, 91, 2985-2993. [CrossRef]

61. Ni, K.F.; Zhou, X.; Zhao, L.; Wang, H.L.; Ren, Y.H.; Wei, D.Z. Magnetic Catechol-Chitosan with Bioinspired Adhesive Surface: Preparation and Immobilization of $\omega$-Transaminase. PLoS ONE 2012, 7, e41101. [CrossRef]

62. Zeng, G.J.; Liu, X.H.; Liu, M.Y.; Huang, Q.; Xu, D.Z.; Wan, Q.; Huang, H.Y.; Deng, F.J.; Zhang, X.Y.; Wei, Y. Facile preparation of carbon nanotubes based carboxymethyl chitosan nanocomposites through combination of mussel inspired chemistry and Michael addition reaction: Characterization and improved $\mathrm{Cu}^{2+}$ removal capability. J. Taiwan Inst. Chem. E 2016, 68, 446-454. [CrossRef]

63. Wang, Y.; Zhang, Y.; Hou, C.; Liu, M.Z. Mussel-inspired synthesis of magnetic polydopamine-chitosan nanoparticles as biosorbent for dyes and metals removal. J. Taiwan Inst. Chem. E 2016, 61, 292-298. [CrossRef]

64. Lei, C.; Wen, F.; Chen, J.; Chen, W.; Wang, B. Mussel-inspired synthesis of magnetic carboxymethyl chitosan aerogel for removal cationic and anionic dyes from aqueous solution. Polymer 2021, 213, 123316. [CrossRef]

65. Szatkowski, T.; Koodziejczak-Radzimska, A.; Zdarta, J.; Szwarc-Rzepka, K.; Jesionowski, T. Synthesis and characterization of hydroxyapatite/chitosan composites. Phys. Probl. Miner. Process. 2015, 51, 575-585.

66. Zhang, C.J.; Hu, M.; Ke, Q.F.; Guo, C.X.; Guo, Y.J.; Guo, Y.P. Nacre-inspired hydroxyapatite/chitosan layered composites effectively remove lead ions in continuous-flow wastewater. J. Hazard. Mater. 2019, 386, 121999. [CrossRef] [PubMed]

67. Ruan, Q.C.; Liberman, D.; Zhang, Y.Z.; Ren, D.; Zhang, Y.P.; Nutt, S.; Janet, M.O. Assembly of Layered Monetite-Chitosan Nanocomposite and Its Transition to Organized Hydroxyapatite. ACS Biomater. Sci. Eng. 2016, 2, 1049-1058. [CrossRef]

68. Ewa, S.Z.; Piotr, J.; Ewa, D.; Małgorzata, K.B.; Łukasz, Z.; Maciej, B.; Alicja, R.K.; Beata, K. Modification of chitosan fibers with short peptides as a model of synthetic extracellular matrix. J. Mol. Struct 2020, 1211, 128061.

69. Guo, L.; An, Q.D.; Xiao, Z.Y.; Zhai, S.R.; Cui, L. Inherent N-doped Honeycomb-like Carbon/ $\mathrm{Fe}_{3} \mathrm{O}_{4}$ Composites with Versatility for Efficient Microwave Absorption and Wastewater Treatment. ACS Sustain. Chem. Eng. 2019, 10, 9237-9248. [CrossRef] 
70. Deng, W.; Tang, S.; Zhou, X.; Liu, Y.; Luo, J. Honeycomb-like structure-tunable chitosan-based porous carbon microspheres for methylene blue efficient removal. Carbohydr. Polym. 2020, 247, 116736. [CrossRef]

71. Zhu, C.; Wu, J.; Jin, X.; Yan, Y.; Ding, C.F.; Tang, K.; Zhang, D. Post-synthesis of biomimetic chitosan with honeycomb-like structure for sensitive recognition of phosphorylated peptides. J. Chromatogr. A 2021, 1643, 462072. [CrossRef] [PubMed]

72. Zou, Q.; Xiong, S.W.; Jiang, M.Y.; Chen, L.Y.; Zheng, K.; Fu, P.G.; Gai, J.G. Highly thermally conductive and eco-friendly oh-hbn/chitosan nanocomposites by constructing a honeycomb thermal network. Carbohydr. Polym. 2021, 266, 118127. [CrossRef] [PubMed]

73. Danner, E.W.; Kan, Y.; Hammer, M.U.; Israelachvili, J.N.; Waite, J.H. Adhesion of mussel foot protein Mefp-5 to mica: An underwater superglue. Biochemistry 2012, 51, 6511-6518. [CrossRef] [PubMed]

74. Yu, M.; Hwang, J.; Deming, T.J. Role of L-3,4-dihydroxyphenylalanine in mussel adhesive proteins. J. Am. Chem. Soc. 1999, 121, 5825-5826. [CrossRef]

75. Waite, J.H. Surface chemistry: Mussel power. Nat. Mater. 2008, 7, 8-9. [CrossRef]

76. Kim, K.; Ryu, J.H.; Lee, D.Y.; Lee, H. Bio-inspired catechol conjugation converts water-insoluble chitosan into a highly watersoluble, adhesive chitosan derivative for hydrogels and LbL assembly. Biomater. Sci. 2013, 1, 783-790. [CrossRef]

77. Kim, E.; Kang, M.; Liu, H.; Cao, C.; Liu, C.; Bentley, W.E.; Qu, X.; Payne, G.F. Pro- and Anti-oxidant Properties of Redox-Active Catechol-Chitosan Films. Front. Chem. 2019, 7, 541. [CrossRef]

78. Lee, D.; Park, J.P.; Koh, M.Y.; Kim, P.; Lee, J.H.; Shin, M.; Lee, H. Chitosan-catechol: A writable bioink under serum culture media. Biomater. Sci. 2018, 6, 1040-1047. [CrossRef]

79. Xu, J.; Strandman, S.; Zhu, J.X.; Barralet, J.; Cerruti, M. Genipin-crosslinked catechol-chitosan mucoadhesive hydrogels for buccal drug delivery. Biomaterials 2015, 37, 395-404. [CrossRef] [PubMed]

80. Zvarec, O.; Purushotham, S.; Masic, A.; Ramanujan, R.V.; Miserez, A. Catechol-functionalized chitosan/iron oxide nanoparticle composite inspired by mussel thread coating and squid beak interfacial chemistry. Langmuir 2013, 29, 10899-10906. [CrossRef]

81. Zeng, Z.; Mo, X. Rapid in situ cross-linking of hydrogel adhesives based on thiol-grafted bio-inspired catechol-conjugated chitosan. J. Biomater. 2017, 32, 612-621. [CrossRef] [PubMed]

82. Zeng, Z.; Mo, X.M.; He, C.; Morsi, Y.; El-Hamshary, H.; El-Newehy, M. An in Situ Forming Tissue Adhesive Based on Poly (ethylene glycol)-Dimethacrylate and Thiolated Chitosan through the Michael Reaction. J. Mater. Chem. B 2016, 4, 5585-5592. [CrossRef]

83. Jenney, C.R.; Anderson, J.M. Adsorbed serum proteins responsible for surface dependent human macrophage behavior. J. Biomed. Mater. Res. 2000, 49, 435-447. [CrossRef]

84. Xie, C.M.; Wang, X.; He, H.; Ding, Y.H.; Lu, X. Mussel-Inspired Hydrogels for Self-Adhesive Bioelectronics. Adv. Funct. Mater. 2020, 30, 1909954. [CrossRef]

85. Yan, S.; Wang, W.; Li, X.; Ren, J.; Yun, W.; Zhang, K.; Li, G.; Yin, J. Preparation of mussel-inspired injectable hydrogels based on dual-functionalized alginate with improved adhesive, self-healing, and mechanical properties. J. Mater. Chem. B 2018, 6, 6377-6390. [CrossRef]

86. Lee, H.; Dellatore, S.M.; Miller, W.M.; Messersmith, P.B. Mussel-inspired surface chemistry for multifunctional coatings. Science 2007, 318, 426-430. [CrossRef]

87. Zhang, S.X.; Zhang, Y.Y.; Bi, G.M.; Liu, J.S.; Wang, Z.G.; Xu, Q.; Xu, H.; Li, X.Y. Mussel-inspired polydopamine biopolymer decorated with magnetic nanoparticles for multiple pollutants removal. J. Hazard. Mater. 2014, 270, 27-34. [CrossRef] [PubMed]

88. Machaowski, T.; Jesionowski, T. Hemolymph of molluscan origin: From biochemistry to modern biomaterials science. Appl. Phys. A 2021, 127, 3. [CrossRef]

89. Addadi, L.; Joester, D.; Nudelman, F.; Weiner, S. Mollusk shell formation: A source of new concepts for understanding biomineralization processes. Chemistry 2006, 12, 980-987. [CrossRef]

90. Podsiadlo, P.; Liu, Z.; Paterson, D.; Messersmith, P.B.; Kotov, N.A. Fusion of seashell nacre and marine bioadhesive analogs: High-strength nanocomposite by layer-by-layer assembly of clay and L-3,4-dihydroxyphenylalanine olymer. Adv. Mater. 2007, 19, 949-955. [CrossRef]

91. Sun, J.; Bhushan, B. Hierarchical structure and mechanical properties of nacre: A review. RSC Adv. 2012, 2, 7617-7632. [CrossRef]

92. Wu, J.; Zhang, L.; Wang, Y.; Long, Y.; Gao, H.; Zhang, X.; Zhao, N.; Cai, Y.; Xu, J. Mussel-inspired chemistry for robust and surface-modifiable multilayer films. Langmuir 2011, 27, 13684-13691. [CrossRef]

93. Bonderer, L.J.; Studart, A.R.; Gauckler, L.J. Bioinspired Design and Assembly of Platelet Reinforced Polymer Films. Science 2008, 319, 1069-1073. [CrossRef] [PubMed]

94. Fujie, T.; Saito, A.; Kinoshita, K.; Miyazaki, H.; Ohtsubo, S.; Saitoh, D.; Takeoka, S. Dual therapeutic action of antibiotic-loaded nanosheets for the treatment of gastrointestinal tissue defects. Biomaterials 2010, 31, 6269-6278. [CrossRef] [PubMed]

95. Cai, L.; Heilshorn, S.C. Designing ECM-mimetic materials using protein engineering. Acta Biomater. 2014, 10, 1751-1760. [CrossRef] [PubMed]

96. Naahidi, S.; Jafari, M.; Logan, M.; Wang, Y.; Bae, H.; Dixon, B.; Chen, P. Biocompatibility of hydrogel-based scaffolds for tissue engineering applications. Biotechnol. Adv. 2017, 35, 530-544. [CrossRef] [PubMed]

97. Badylak, S.; Freytes, D.; Gilbert, T. Extracellular matrix as a biological scaffold material: Structure and function. Acta Biomater. 2009, 5, 1-13. [CrossRef] 
98. Huang, G.Y.; Li, F.; Zhao, X.; Ma, Y.F. Functional and Biomimetic Materials for Engineering of the Three-Dimensional Cell Microenvironment. Chem. Rev. 2017, 117, 12764-12850. [CrossRef]

99. Jain, D.; Mattiassi, S.; Goh, E.L.; Yim, E.K. Extracellular matrix and biomimetic engineering microenvironment for neuronal differentiation. Neural Regen Res. 2020, 15, 7-19.

100. Bawazer, L.A.; McNally, C.S.; Empson, C.J.; Marchant, W.J.; Comyn, T.P.; Niu, X.; Cho, S.; McPherson, M.J.; Binks, B.P.; deMello, A.; et al. Combinatorial microfluidic droplet engineering for biomimetic material synthesis. Sci. Adv. 2016, 2, e1600567. [CrossRef]

101. Hosseinkhani, H.; Hiraoka, Y.; Li, C.H.; Chen, Y.R.; Yu, D.S.; Hong, P.D.; Ou, K.L. Engineering three-dimensional collagen-IKVAV matrix to mimic neural microenvironment. ACS Chem. Neurosci. 2013, 4, 1229-1235. [CrossRef]

102. Wang, Z.; Wang, C.; Abudukeremu, A.; Rui, X.; Liu, S.; Zhang, X.; Zhang, M.; Zhang, J.; Dong, L. Engineering a Tumor Microenvironment-Mimetic Niche for Tissue Regeneration with Xenogeneic Cancer Cells. Adv. Sci. (Weinh.) 2018, 5, 1700666. [CrossRef] [PubMed]

103. Kim, B.S.; Mooney, D.J. Development of biocompatible synthetic extracellular matrices for tissue engineering. Trends Biotechnol. 1998, 16, 224-230. [CrossRef]

104. Singh, M.; Berkland, C.; Detamore, M.S. Strategies and applications for incorporating physical and chemical signal gradients in tissue engineering. Tissue Eng. Part. B Rev. 2008, 14, 341-366. [CrossRef] [PubMed]

105. Wenger, M.P.; Bozec, L.; Horton, M.A.; Mesquida, P. Mechanical properties of collagen fibrils. Biophys. J. 2007, 93, 1255-1263. [CrossRef] [PubMed]

106. Bharadwaz, A.; Jayasuriya, A.C. Recent trends in the application of widely used natural and synthetic polymer nanocomposites in bone tissue regeneration. Mater. Sci. Eng. C 2020, 110, 110698. [CrossRef]

107. Kazimierczak, P.; Benko, A.; Nocun, M.; Przekora, A. Novel chitosan/agarose/hydroxyapatite nanocomposite scaffold for bone tissue engineering applications: Comprehensive evaluation of biocompatibility and osteoinductivity with the use of osteoblasts and mesenchymal stem cells. Int. J. Nanomed. 2019, 14, 6615-6630. [CrossRef]

108. Lu, H.T.; Lu, T.W.; Chen, C.H.; Mi, F.L. Development of genipin-crosslinked and fucoidan-adsorbed nano-hydroxyapatite/ hydroxypropyl chitosan composite scaffolds for bone tissue engineering. Int. J. Biol. Macromol. 2019, 128, 973-984. [CrossRef]

109. Parker, A.R.; Lawrence, C.R. Water capture by a desert beetle. Nature 2001, 414, 33-34. [CrossRef]

110. Garrod, R.P.; Harris, L.G.; Schofield, W.C.; Mcgettrick, J.; Ward, L.J.; Teare, D.O.; Badyal, J.P. Mimicking a Stenocara beetle's back for microcondensation using plasmachemical patterned superhydrophobic-superhydrophilic surfaces Langmuir. ACS J. Surf. Colloids 2007, 23, 689-693. [CrossRef]

111. Park, K.C.; Kim, P.; Grinthal, A.; He, N.; Fox, D.; Weaver, J.C.; Aizenberg, J. Condensation on slippery asymmetric bumps. Nature 2016, 531, 78-82. [CrossRef]

112. Cao, M.; Xiao, J.; Yu, C.; Li, K.; Jiang, L. Hydrophobic/hydrophilic cooperative janus system for enhancement of fog collection. Small 2015, 11, 4379-4384. [CrossRef] [PubMed]

113. Liu, M.; Peng, Z.L.; Yao, Y.; Yang, Y.Z.; Chen, S.H. A flexible functional surface for efficient water collection. ACS Appl. Mater. Interfaces 2020, 12, 12256-12263. [CrossRef] [PubMed]

114. Yu, Z.L.; Yang, N.; Zhou, L.C.; Ma, Z.Y.; Zhu, Y.B.; Lu, Y.Y.; Qin, B.; Xing, W.Y.; Ma, T.; Li, S.C.; et al. Bioinspired polymeric woods. Sci. Adv. 2018, 4, eaat7223. [CrossRef] [PubMed] 